\title{
Distinct Effects of IL-6 Classic and Trans-Signaling in Bone Fracture Healing
}

Katja Prystaz, ${ }^{*}$ Kathrin Kaiser, ${ }^{*}$ Anna Kovtun, ${ }^{*}$ Melanie Haffner-Luntzer, ${ }^{*}$ Verena Fischer, ${ }^{*}$ Anna E. Rapp, ${ }^{*}$ Astrid Liedert, ${ }^{*}$ Gudrun Strauss, ${ }^{\dagger}$ Georg H. Waetzig, ${ }^{\ddagger}$ Stefan Rose-John, ${ }^{\S}$ and Anita Ignatius*

From the Institute of Orthopedic Research and Biomechanics, * Trauma Research Center Ulm, and the Department of Pediatrics and Adolescent Medicine, University Medical Center Ulm, Ulm; the CONARIS Research Institute AG, ${ }^{\ddagger}$ Kiel; and the Institute of Biochemistry, ${ }^{\S}$ Christian-Albrechts-University of Kiel, Kiel, Germany

\author{
Accepted for publication \\ October 19, 2017. \\ Address correspondence to \\ Anita Ignatius, D.V.M., Insti- \\ tute of Orthopedic Research \\ and Biomechanics, University \\ Medical Center Ulm, Helm- \\ holtzstrasse 14, Ulm 89081, \\ Germany. E-mail: anita. \\ ignatius@uni-ulm.de.
}

\begin{abstract}
Bone healing is a complex process with closely linked phases of inflammation, regeneration, and remodeling. IL-6 may crucially regulate this process; however, the underlying mechanisms are unclear. IL- 6 signals are transmitted via the transmembrane glycoprotein 130 by two distinct mechanisms: classic signaling using the membrane-anchored IL-6 receptor and trans-signaling using its soluble form. Herein, we investigated the hypothesis that IL- 6 classic and trans-signaling have different functions

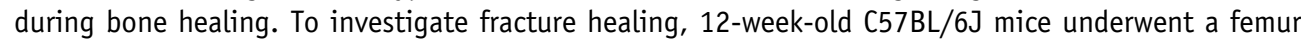
osteotomy. To study the function of IL-6 during the inflammatory phase, either an anti-IL- 6 antibody, which inhibits IL-6 classic and trans-signaling, or soluble glycoprotein 130 fusion protein, which selectively blocks trans-signaling, was injected after 30 minutes and 48 hours. To analyze IL- 6 effects in the repair phase, compounds were injected from day 7 onwards. Global IL-6 inhibition in the early phase after fracture reduced systemic inflammation, the recruitment of immune cells, and bone regeneration, resulting in delayed fracture healing. Global IL-6 inhibition during the repair phase disturbed bone formation and remodeling. In contrast, inhibition of IL- 6 trans-signaling exerted minor effects on the immune response and did not influence bone repair, suggesting that the classic pathway accounts for most of the effects observed after global IL-6 inhibition. Our results reveal that IL-6 classic signaling, but not IL-6 trans-signaling, is essential for bone repair. (Am J Pathol 2018, 188: 474-490; https:/) doi.org/10.1016/j.ajpath.2017.10.011)
\end{abstract}

Bone healing after fracture is a complex process with overlapping phases of inflammation, granulation tissue formation, intramembranous and endochondral ossification, and, finally, remodeling of the initially formed woven to lamellar bone until the original shape is restored. ${ }^{1,2}$ The healing process is orchestrated by a complex network of inflammatory, angiogenic, osteoanabolic, and osteocatabolic mediators, which is only incompletely understood. ${ }^{3,4}$ IL-6, a pleiotropic cytokine exerting both proinflammatory and anti-inflammatory effects, may play a key regulatory role in the complex fracture-healing cascade. Therefore, healing complications occur more frequently in patients with inflammatory disorders, which are often associated with increased circulating IL-6 levels, including osteoporosis, rheumatoid arthritis, and diabetes. ${ }^{5-7}$ In patients with multiple trauma, who frequently experience fractures and display high IL-6 concentrations, ${ }^{8}$ the risk for fracture malunion increases up to $50 \%$, dependent on injury severity. ${ }^{9,10}$ Furthermore, clinical and experimental studies have linked high IL-6 expression in the fracture callus to compromised healing. ${ }^{11,12}$

Supported by the German Research Foundation in the context of the Collaborative Research Center (CRC) Danger response, disturbance factors, and regenerative potential after acute trauma grant CRC1149, INST40/4911 (A.I.).

Disclosures: S.R.-J. is a shareholder of the CONARIS Research Institute AG (Kiel, Germany), which is commercially developing soluble glycoprotein 130 fusion proteins (sgp130Fes) as therapeutics for inflammatory diseases; G.H.W. is an employee of the CONARIS Research Institute AG; S.R.-J. and G.H.W. are inventors on patents describing the function of sgp130Fc. 
Although the role of IL-6 in physiological bone turnover has been extensively investigated, demonstrating that it modulates both osteoblast and osteoclast activity, ${ }^{13}$ much less is known about its function in fracture healing. Existing studies are merely descriptive. IL-6 expression in the fracture callus is considered to be biphasic. It peaks first during the acute inflammatory phase after fracture, when it is regarded to induce the recruitment of immune cells and stimulate angiogenesis. ${ }^{3,14}$ Later, IL-6 expression increases again and may regulate intramembranous and endochondral ossification as well as callus remodeling. ${ }^{3,15}$ Investigations of the mechanistic function of IL-6 during fracture healing are limited; however, its significance was indicated by experiments using mice with a global IL-6 knockout. Yang et $\mathrm{al}^{16}$ reported poor callus mineralization, an increased cartilage fraction, and a reduced osteoclast number during the early repair phase. A second study described impaired callus strength and decreased osteoclast numbers in the absence of IL- 6 in the early healing stage, whereas later there was a trend toward enhanced callus stiffness, ${ }^{17}$ indicating that IL-6 might have distinct functions at different healing stages. A limitation of these studies is that a global IL-6 knockout leads to dysfunctions in several biological systems (eg, hematopoietic, endocrine, and neuronal systems), ${ }^{18-22}$ which may consequently interfere with bone healing. Furthermore, these studies did not discriminate between different IL- 6 signaling pathways, which may possibly provoke diverse effects during bone repair.

The IL-6 signal is transmitted via two different mechanisms. In IL-6 classic signaling, IL-6 binds to its specific membrane-anchored receptor (mIL-6R), which, in turn, associates with two molecules of the transmembrane glycoprotein 130 (gp130). This leads to intracellular signal transduction, involving the Janus kinase/STAT, mitogenactivated protein kinase, and phosphoinositide 3-kinase pathways. ${ }^{23}$ The mIL-6R is mainly found on immune cells and hepatocytes, whereas gp130 is expressed by virtually all cell types, including osteoblasts and osteoclasts. ${ }^{24,25}$ These cells can be activated by IL- 6 trans-signaling, in which IL-6 binds to its soluble receptor (sIL-6R) and then to the gp130 dimer. sIL-6R is preferentially secreted from innate immune cells, including neutrophils, after proteolytic cleavage of the membrane-bound IL-6R by the zinc a disintegrin and metalloproteinases 10 and 17 or, to a lesser extent, from alternative splicing. ${ }^{26}$ It is postulated that IL-6 trans-signaling acts as a danger signal driving proinflammatory reactions, whereas IL-6 classic signaling rather mediates antiinflammatory and regenerative responses. ${ }^{25,27}$ To our knowledge, studies discriminating between the roles of both IL-6 signaling pathways in the inflammatory response to fracture and bone healing are lacking. More important, a better molecular understanding of IL-6 actions may have therapeutic implications for patients with fracture healing complications.

Herein, we investigated the hypothesis that IL-6 classic and trans-signaling have divergent functions in the chronology of bone healing. A standardized mouse model for uneventful fracture healing was used to systematically compare the following: global inhibition of IL-6 classic and trans-signaling using an anti-IL-6 antibody; and specific inhibition of IL-6 trans-signaling using soluble gp130 fusion protein $(\operatorname{sgp} 130 \mathrm{Fc})$, an artificial fusion protein, which selectively neutralizes the IL-6/sIL-6R complex. ${ }^{28}$ To study IL-6 action during different phases of fracture healing, the inhibitors were applied either during the early inflammatory phase after fracture or later during bone formation.

\section{Materials and Methods}

\section{Femur 0steotomy}

All animal experiments were performed according to the European Union Directive 2010/63/EU and Animal Research: Reporting of in Vivo Experiments guidelines and were approved by the responsible Local Ethical Committee (1166 and 1247; Regierungspräsidium, Tübingen, Germany). Male, 12-week-old, C57BL/6J mice $(n=152)$ were purchased from Charles River (Sulzfeld, Germany) and were provided with water and food ad libitum. The femur osteotomy was performed as described previously. ${ }^{29}$ Briefly, under general anesthesia with 2\% isoflurane (Forene; Abbott, Wiesbaden, Germany), an osteotomy gap was generated using a 0.4-mm Gigli saw (RISystem, Davos, Switzerland) at the midshaft of the femur and stabilized using an external fixator (RISystem). For pain medication, an analgesic [25 mg/ $\mathrm{mL}$ tramadol hydrochloride (Tramal); Gruenenthal GmbH, Aachen, Germany] was administered via the drinking water starting 1 day before surgery until 3 days after surgery. To discriminate between IL- 6 classic and trans-signaling, the following inhibitors were intraperitoneally administered. For trans-signaling inhibition, $0.5 \mathrm{mg} / \mathrm{kg} \mathrm{sgp} 130 \mathrm{Fc}$ (CONARIS Research Institute AG, Kiel, Germany), a fusion protein of the extracellular domain of gp 130 dimerized by the $\mathrm{Fc}$ domain of human IgG1, which selectively binds to the IL-6/sIL-6R complex, was injected. For global IL-6 blockade, $2 \mathrm{mg} / \mathrm{kg}$ of a well-characterized neutralizing rat anti-murine anti-IL-6 antibody (clone MP5-20F3; BD Biosciences, Heidelberg, Germany), which blocks both IL-6 classic and transsignaling, ${ }^{30}$ was administered. It is not possible to inhibit selectively classic IL-6 signaling. However, by comparing the effects of global and trans-signaling inhibition, indirect, but valid, conclusions can be drawn about the impact of classic IL-6 signaling.

To investigate the influence of IL- 6 during the inflammatory phase, the mice were intraperitoneally injected with either sgp130Fc or anti-IL-6 antibody 30 minutes and 48 hours after femur osteotomy. To study the role of IL-6 during bone regeneration, the mice received the inhibitors on days 7, 10, 13, and 17 after osteotomy. Control mice received phosphate-buffered saline (Fisher Scientific $\mathrm{GmbH}$, Schwerte, Germany) or rat IgG1 isotype control antibody (BD Biosciences) (Supplemental Table S1). The 
mice were euthanized 3 hours or $1,3,10,14$, or 21 days after surgery using an isoflurane overdose and terminal cardiac puncture ( $n=5$ to 8 per group at each time point).

\section{Multiplex Cytokine Analysis and Enzyme-Linked Immunosorbent Assay}

To assess posttraumatic inflammation, plasma and serum samples were obtained 3 and 24 hours after osteotomy. The fracture hematoma was harvested 3 hours after surgery and lysed in buffer $(10 \mathrm{mmol} / \mathrm{L}$ Tris, $\mathrm{pH} 7.5,10 \mathrm{mmol} / \mathrm{L} \mathrm{NaCl}$, $0.1 \mathrm{mmol} / \mathrm{L}$ EDTA, $0.5 \mathrm{mmol} / \mathrm{L}$ Triton X-100, $0.02 \%$ sodium azide, and $0.2 \mathrm{mmol} / \mathrm{L}$ phenylmethanesulfonyl fluoride) containing protease inhibitors (Halt Protease and Phosphatase Inhibitor Single-Use Cocktail; Fisher Scientific $\mathrm{GmbH}$ ). Total protein concentration was determined using the Pierce BCA Protein Assay Kit (Fisher Scientific GmbH). Plasma and hematoma concentrations of IL- 6 , IL-1 $\beta$, tumor necrosis factor- $\alpha$, IL-10, CXCL1, monocyte chemotactic protein 1 , interferon- $\gamma$, IL-13, IL-4, and macrophage inflammatory protein- $1 \alpha$ were determined using a mouse Multiplex Cytokine Kit (ProcartaPlex; eBioscience, Frankfurt, Germany). The plasma concentrations of C-reactive protein (CRP) were determined using a mouse Multiplex ProcartaPlex Simplex Kit (Fisher Scientific GmbH). Data were analyzed using the Luminex 100 Total System (BioRad Laboratories, Hercules, CA). All fracture hematoma cytokine values were normalized to the homogenate protein concentration. To determine physiological levels of inflammatory mediators, an additional mouse group was included, which did not receive any treatment (nonfractured mice; $n=3$ to 4 ). The serum levels of sIL-6R were determined using a mouse sIL-6R enzyme-linked immunosorbent assay (R\&D Systems, Minneapolis, MN), according to the manufacturer's protocol.

\section{Western Blot Analysis}

To test the efficacy of IL-6 inhibition, the induction of intracellular IL-6 signaling was analyzed by determining STAT3 phosphorylation in hepatocytes, which express high levels of mIL-6R. ${ }^{31}$ The liver was harvested 3 and 72 hours after surgery, homogenized using a mixer mill (model MM400; Retsch GmbH, Haan, Germany), lysed in buffer [50 mmol/L Tris- $\mathrm{HCl}, \mathrm{pH} 7.5,250 \mathrm{mmol} / \mathrm{L} \mathrm{NaCl}, 3 \mathrm{mmol} / \mathrm{L}$ EDTA, $3 \mathrm{mmol} / \mathrm{L}$ ethylene glycol-bis(2-aminoethylether)$\mathrm{N}, \mathrm{N}, \mathrm{N}^{\prime}, \mathrm{N}^{\prime}$-tetraacetic acid, $1 \%$ Triton $\mathrm{X}-100,0.5 \%$ Nonidet $\mathrm{P} 40$, and $10 \%$ glycerol] containing protease inhibitors (Halt Protease and Phosphatase Inhibitor Single-Use Cocktail), and further processed similarly to the fracture hematoma homogenates.

Equal amounts (10 to $30 \mu \mathrm{g}$ ) of lysate protein were resolved using SDS-PAGE and transferred to a nitrocellulose membrane (Amersham Hyperfilm ECL; GE Healthcare Life Sciences, Chicago, IL). The membranes were incubated overnight at $4{ }^{\circ} \mathrm{C}$ with antibodies against the housekeeping control, glyceraldehyde 3-phosphate dehydrogenase, phosphorylated STAT3 (pSTAT3), or total STAT3 (all from Cell Signaling Technology, Darmstadt, Germany). Protein bands were visualized as described previously. ${ }^{32}$

\section{Real-Time PCR}

The liver samples were stored in RNAlater-ICE Frozen Tissue Transition Solution (Fisher Scientific GmbH). After removing the RNAlater solution, samples were homogenized using a mixer mill (Western Blot Analysis) and incubated with $1 \mathrm{~mL}$ Trizol for 5 minutes. After adding 0.2 $\mathrm{mL}$ chloroform, the samples were centrifuged at 12,000 $\times \mathrm{g}$ for 30 minutes, and liver RNA was isolated using the PureLink RNA MiniKit (Fisher Scientific GmbH), according to the manufacturer's instructions.

Reverse transcription of $1 \mu \mathrm{g}$ of total RNA was performed using the Omniscript RT Kit (Qiagen, Hilden, Germany), according to the manufacturer's instructions. Quantitative PCR was performed using the Brilliant SYBR Green MasterMix Kit (Stratagene, Amsterdam, the Netherlands). Each sample was tested in duplicate using the following cycling conditions: $50^{\circ} \mathrm{C}$ for 2 minutes, $95^{\circ} \mathrm{C}$ for 2 minutes, and 40 cycles each consisting of $95^{\circ} \mathrm{C}$ for 15 seconds and $60^{\circ} \mathrm{C}$ for 1 minute. Glyceraldehyde 3-phosphate dehydrogenase (Gapdh; forward, 5'-ACCCAGAAGACTGTGGATGG-3'; and reverse, 5'-GGATGCAGGGATGATGTTCT- $3^{\prime}$ ) was used as the housekeeping gene. The expression of chemokines, cytokines, and acute-phase proteins was analyzed using specific primers for CXCL1 ( $\mathrm{Cxcll}$; forward, 5'-TCTCCGTTACTTGGGGACAC-3'; and reverse, 5' CCACACTCAAGAATGGTCGC- ${ }^{\prime}$ ), serum amyloid A ( $\mathrm{Saa}$; forward, 5'-GACACCAGGATGAAGCTACTCA-3'; and reverse, 5'-CTTGGAAAGCCTCGTGAACA-3'), and CRP ( $C r p$; forward, 5'-ATCCCAGCAGCATCCATAGC-3'; and reverse, 5'-AACATGTCTTCATGACCAAAAGTCC-3'). Relative gene expression was calculated using the $\Delta \Delta \mathrm{C}_{\mathrm{T}}$ method, with PCR efficiency correction using LinRegPCR 2015.3 (Academic Medical Center, Amsterdam, the Netherlands $\left.{ }^{33}\right) . \mathrm{C}_{\mathrm{T}}$ values obtained for each sample were normalized to those of the housekeeping gene glyceraldehyde 3-phosphate dehydrogenase.

\section{Flow Cytometry}

The presence of inflammatory cells in the fracture hematoma was analyzed by flow cytometry. The hematoma was collected 1 day after osteotomy and passed through a cell strainer with a 70- $\mu \mathrm{m}$ mesh (Corning Inc., Durham, NC) to obtain a single-cell suspension. The resulting isolated cells were stained with the following antibodies: anti-Ly-6GV450 (560603; BD Biosciences), anti-CD11b-Alexa Fluor 700 (56-0112; eBioscience), anti-F4/80-fluorescein isothiocyanate (11-4801; eBioscience), anti-CD3ephosphatidylethanolamine-cyanine 7 (25-0031; eBioscience), anti-CD19-phosphatidylethanolamine (12-0193; eBioscience), anti-IL-6-phosphatidylethanolamine (504503; 
BioLegend, Fell, Germany), phosphatidylethanolamine antipSTAT3 (Tyr705; 651003; BioLegend), anti-IL-6R-Alexa Fluor 700 (FAB1830N; R\&D Systems), anti-gp130-Alexa Fluor 700 (FAB4681N; R\&D Systems), anti-CD11b-APCCy7 (557657; BD Biosciences), and anti-CD19-APC (152409; BioLegend). They were used against the indicated surface markers for 30 minutes on ice: neutrophils $\left(\mathrm{Ly}-6 \mathrm{G}^{+}\right.$and $\mathrm{CD} 11 \mathrm{~b}^{+}$), macrophages (Ly-6G ${ }^{-}, \mathrm{F} 4 / 80^{+}$, and $\left.\mathrm{CD} 11 \mathrm{~b}^{+}\right)$, B cells $\left(\mathrm{CD}^{-}\right.$and $\left.\mathrm{CD} 19^{+}\right)$, $\mathrm{T}$ cells $\left(\mathrm{CD}^{+}\right.$ and $\mathrm{CD} 19^{-}$), IL-6R, and gp130. For intracellular staining, the cells were fixed for 15 minutes at $37^{\circ} \mathrm{C}$ with $0.4 \%$ formalin and permeabilized with $0.1 \%$ Triton X-100. Subsequently, cells were stained for IL- 6 and pSTAT3 for 30 minutes on ice. Corresponding isotype-matched controls from the respective manufacturers were used as negative controls. To discriminate dead cells, 7-aminoactinomycin (Sigma-Aldrich, Taufkirchen, Germany) was used. The samples were analyzed using an LSR II flow cytometer (BD Biosciences) and FlowJo software version 10.0.8r1 (FlowJo, Ashland, OR).

\section{Histomorphometry and Immunohistochemistry}

Fractured femurs were embedded in paraffin (days 3, 10, 14, and $21 ; n=5$ to 6 per group) or in methyl methacrylate (day $21 ; n=6$ to 8 per group). For immunochemical and histochemical staining, the fractured femurs were harvested with surrounding tissues and fixed in $4 \%$ buffered formalin solution (Otto Fischar GmbH \& Co KG, Saarbruecken, Germany). For immunohistochemistry, fractured femurs were decalcified using 20\% EDTA (pH 7.2 to 7.4) for 10 to 12 days and embedded in paraffin after dehydration in an ascending ethanol series. For histology without decalcification, femurs were fixed in $4 \%$ formalin for 48 hours, dehydrated in an ascending ethanol series, and embedded in methyl methacrylate. For tissue quantification, femur sections were stained with Safranin-O (Merck Chemicals $\mathrm{GmbH}$, Darmstadt, Germany) or Giemsa (AppliChem, Darmstadt, Germany). The relative amounts of osseous, cartilage, and fibrous tissues were evaluated in the callus between the two inner pinholes using image analysis software MMAF version 1.4.0 MetaMorph (Leica, Heerbrugg, Switzerland). Tartrate-resistant acid phosphatase staining was used to identify osteoclasts. ${ }^{34}$ Paraffin-embedded sections of fractured femurs were stained using the following antibodies and dilutions: IL-6 (1:250 rabbit anti-IL-6 polyclonal antibody; bs-0782R; Bioss, Woburn, MS), IL-6R (1:500 rabbit anti-IL-6R polyclonal antibody; bs-1805R; Bioss), gp130 (1:250 rabbit anti-gp130 polyclonal antibody; bs-1459R; Bioss), pSTAT3 [1:100 rabbit antipSTAT3 (Tyr705) antibody; 9145; Cell Signaling Technology], anti-IL-6 (1:50 goat anti-rat IgG antibody; A10517; Life Technologies GmbH, Darmstadt, Germany), sgp130Fc (1:100 human IgG Fc; I2136; Sigma-Aldrich), neutrophil granulocytes (1:300 LEAF anti-mouse Ly-6G antibody; 127632; BioLegend), macrophages (1:500 rat anti-mouse F4/80 antibody; MCA497GA; AbD Serotec, Puchheim, Germany), CD8 T cells (1:500 rabbit anti-CD8 antibody; bs-0648R; Bioss), receptor activator of NF- $\kappa \mathrm{B}$ ligand (RANKL; 1:100 goat anti-mouse RANKL polyclonal antibody; sc-7628; Santa Cruz Biotechnology, Dallas, TX), runt-related transcription factor 2 (1:50 rabbit anti-mouse runt-related transcription factor 2 antibody; 8486; Cell Signaling Technology), and secondary antibodies [1:100 goat anti-rabbit IgG secondary antibody (B2770; Life Technologies), 1:200 goat anti-rat IgG secondary antibody (A10517; Life Technologies), and 1:200 rabbit anti-goat IgG secondary antibody (A10518; Life Technologies)]. Species-specific IgG subtype mixtures obtained from the respective manufacturers were used as negative controls. Primary antibody binding was detected using Vectastain Elite ABC Kit and NovaRed substrate (both from Vector, Burlingame, CA). Sections were counterstained with hematoxylin (Waldeck, Münster, Germany). Stained femurs were analyzed by light microscopy (Leica DMI6000B; Leica). Quantification of the positively stained regions for IL-6, IL-6R, gp130, and pSTAT3 in the periosteal fracture callus was performed using the image analysis software Adobe Photoshop CS6 (Adobe System Software, Dublin, Ireland), as described previously.

\section{Biomechanical Testing}

For functional testing, biomechanical analysis of intact and fractured femurs explanted on day 21 was performed using a nondestructive three-point bending test. ${ }^{29}$ In brief, after removal of the fixator, an axial load with a maximum of $4 \mathrm{~N}$ was applied to the top of the craniolateral callus side. The bending stiffness was calculated using the slope of the loaddeflection curve.

\section{Micro-Computed Tomography}

After biomechanical testing, the femurs were fixed in $4 \%$ buffered formalin solution (Otto Fischar $\mathrm{GmbH} \& \mathrm{Co} \mathrm{KG}$ ) and then immediately analyzed using a micro-computed tomography scanning device (Skyscan 1172 1.5; Bruker, Kontich, Belgium) operating at a voxel resolution of $8 \mu \mathrm{m}(50 \mathrm{kV}, 200$ $\mathrm{mA})$. The volume of interest included the osteotomy gap and the periosteal callus between the fractured cortices. Bone mineral density was determined using two phantoms with a defined hydroxyapatite density $\left(250\right.$ and $\left.750 \mathrm{mg} / \mathrm{cm}^{3}\right)$ within each scan. Mineralized and nonmineralized tissues were distinguished using a global threshold of $642 \mathrm{mg}$ hydroxyapatite $/ \mathrm{cm}^{3},{ }^{36}$ and in accordance with the American Society for Bone and Mineral Research guidelines for micro-computed tomography analysis. ${ }^{37}$ Three-dimensional reconstructions of the periosteal fracture callus between the two inner pinholes were generated using CTvol software version 2.2.2.1 (Bruker). For the assessment of the bony bridging of the osteotomy gap, the number of bridged cortices per fracture callus was evaluated in two perpendicular planes using micro-computed 

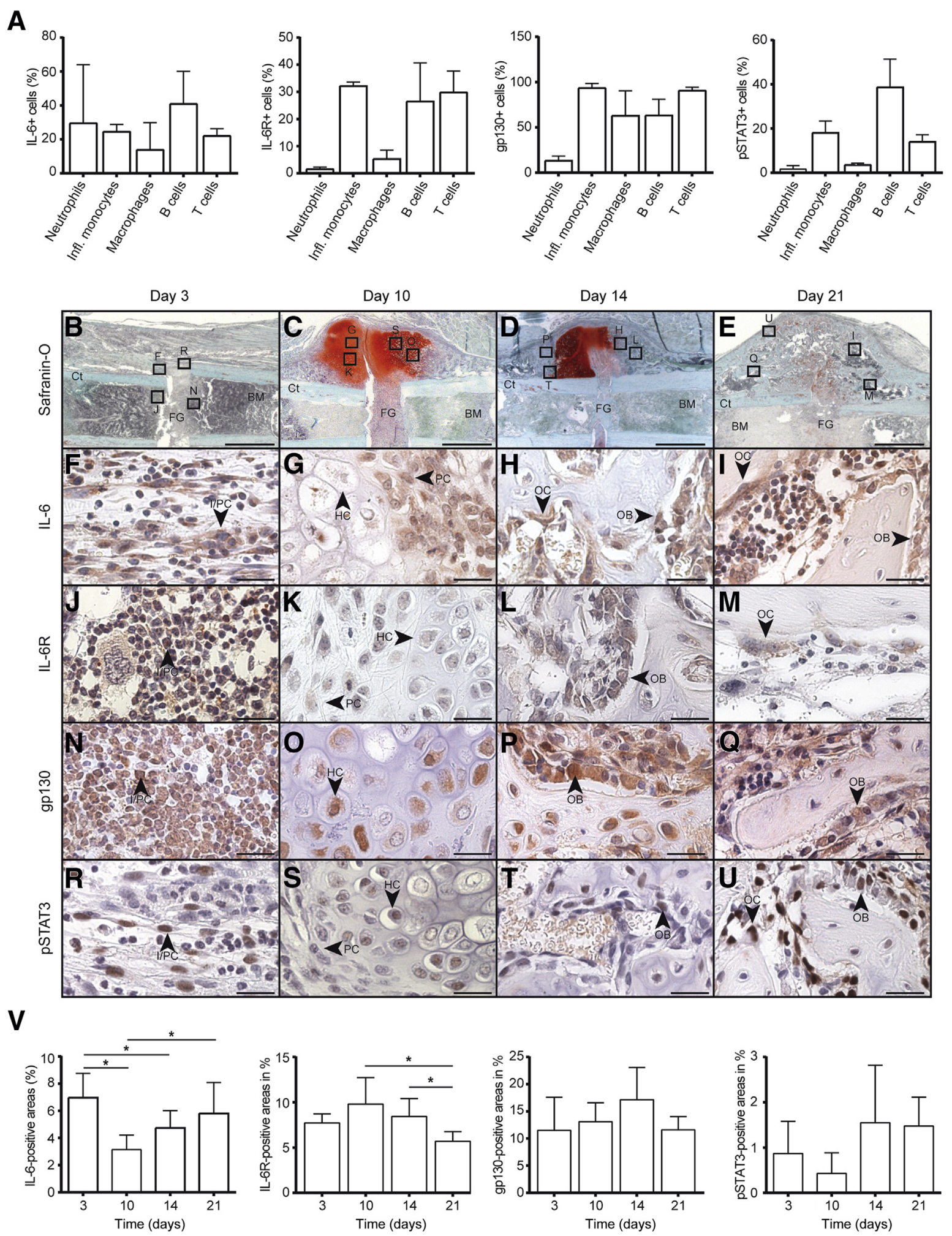

Figure 1 Immune cell staining of IL-6, membrane-anchored receptor IL-6 (mIL-6R), glycoprotein 130 (gp130), and phosphorylated STAT3 (pSTAT3) in the fracture callus. A: IL-6-, mIL-6R-, gp130-, and pSTAT3-positive immune cells in the fracture hematoma 1 day after fracture, analyzed by flow cytometry. B-E: Representative images of the fracture callus stained with Safranin-0 on days 3,10,14, and 21. Boxed areas in $\mathbf{B}-\mathbf{E}$ are shown at higher magnification in $\mathbf{F}-\mathbf{U}$. F-U: IL-6 (F-I), mIL-6R (J-M), gp130 (N-Q), and pSTAT3 (R-U) immunohistochemical staining in the fracture callus of wild-type mice. Arrowheads indicate some of the positively stained cells. V: Quantification of the IL-6-, IL-6R-, gp130-, and pSTAT3-positive areas (in percentage). Data are expressed as means $\pm \mathrm{SD}(\mathbf{A}$ and $\mathbf{V}) . n=4(\mathbf{A}) ; n=5$ to $6(\mathbf{V}) .{ }^{*} P<0.05$. Scale bars: $750 \mu \mathrm{m}(\mathbf{B}-\mathbf{E}) ; 25 \mu \mathrm{m}(\mathbf{F}-\mathbf{U})$. Original magnification: $\times 12.5(\mathbf{B}-\mathbf{E}) ; \times 40(\mathbf{F}-\mathbf{U})$. BM, bone marrow; $\mathrm{Ct}$, cortex; FG, fracture gap; $\mathrm{HC}$, hypertrophic chondrocyte; Infl., inflammatory; I/PC, immune/precursor cell; $0 \mathrm{~B}$, osteoblast; $\mathrm{OC}$, osteoclast; $\mathrm{PC}$, proliferating chondrocyte. 

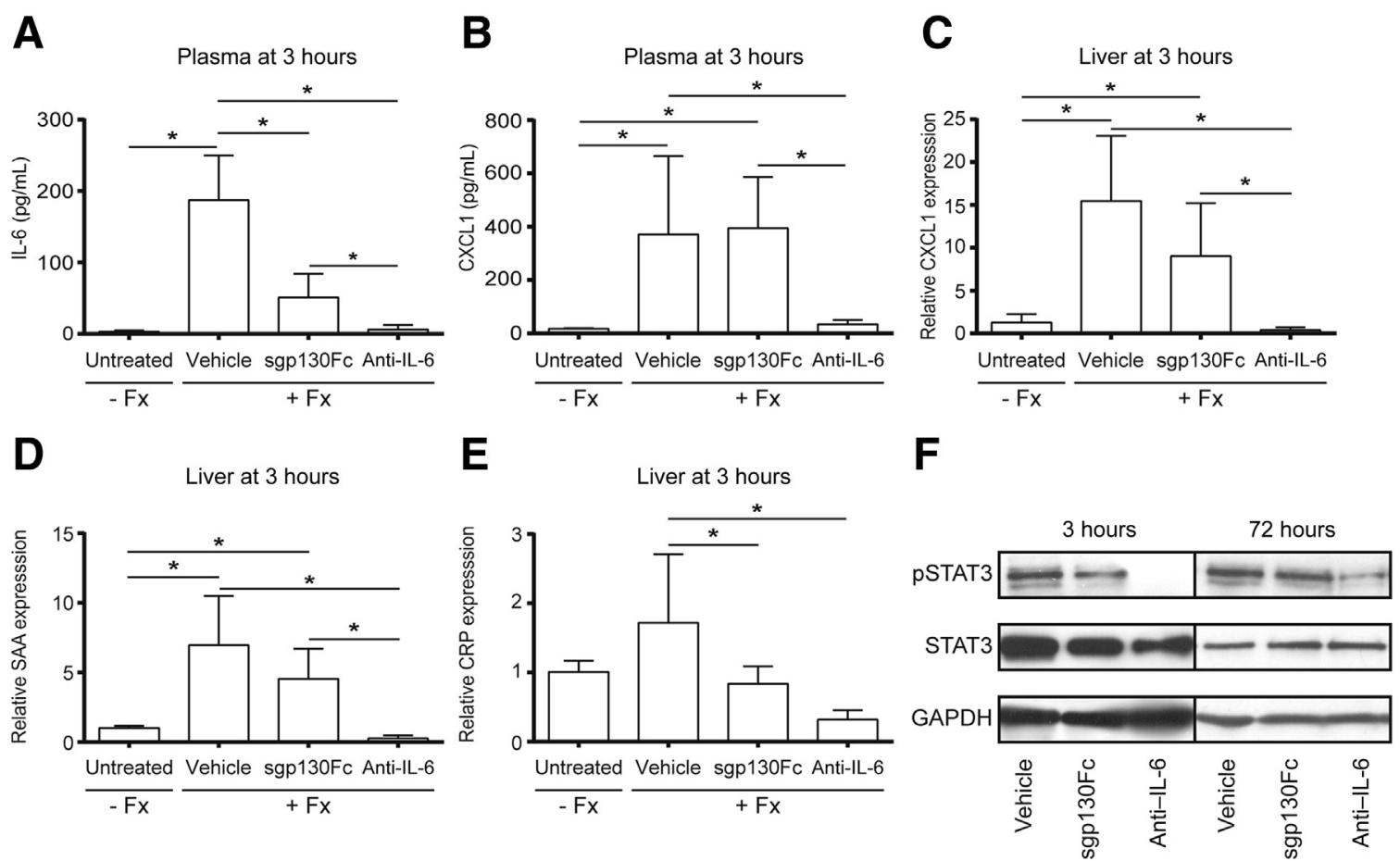

Figure 2 Cytokines and chemokines in plasma and liver. A and B: IL-6 (A) and CXCL1 (B) concentrations in the plasma of vehicle-, soluble glycoprotein 130 fusion protein $(\mathrm{sgp} 130 \mathrm{Fc})-$, and anti-IL-6 antibody-treated mice 3 hours after fracture (Fx) and untreated nonfractured mice. C-E: Relative gene expression of CXCL1, serum amyloid A (SAA), and C-reactive protein (CRP) in the liver. F: Western blot analysis of phosphorylated STAT3 (pSTAT3) and STAT3 of liver homogenates 3 and 72 hours after fracture. Data are expressed as means \pm SD $(\mathbf{A}-\mathbf{E}) . n=4$ to $6(\mathbf{A}$ and $\mathbf{B}) ; n=3$ to $6(\mathbf{C}-\mathbf{E})$. ${ }^{\star} P<0.05$. GAPDH, glyceraldehyde 3-phosphate dehydrogenase.

tomography images. The fracture was considered as successfully healed when three or more bridged cortices per callus were detected.

\section{Data and Statistical Analysis}

Statistical analysis was performed using GraphPad Prism version 6.07 (GraphPad Software, La Jolla, CA). Data were tested for normal distribution using a Shapiro-Wilk test.
Statistical significance was evaluated by either one-way analysis of variance and the Fisher least significant difference post hoc test or a $t$-test. The level of significance was set to $P<0.05$. Sample size was calculated on the basis of the main outcome parameter of flexural rigidity of the fractured femur (power, 80\%; $\alpha=0.05$ ) obtained from previous studies. ${ }^{32}$ All results are presented as the means \pm SD. Sample size was $n=3$ to 8 per group and time point.

Table 1 Cytokine and Chemokine Concentrations in Plasma 3 Hours after Fracture

\begin{tabular}{|c|c|c|c|c|}
\hline \multirow[b]{3}{*}{ Cytokine/chemokine } & \multicolumn{4}{|c|}{ Plasma concentration, $\mathrm{pg} / \mathrm{mL}$} \\
\hline & \multirow[b]{2}{*}{ Nonfractured mice } & \multicolumn{3}{|c|}{3 hours after fracture } \\
\hline & & Vehicle & sgp130Fc & Anti-IL-6 \\
\hline TNF- $\alpha$ & ND & ND & ND & ND \\
\hline MCP-1 & $18.13 \pm 9.0$ & $24.5 \pm 15.91$ & $19.13 \pm 12.14$ & $29.03 \pm 9.25$ \\
\hline IL-13 & $3.76 \pm 7.51$ & $4.86 \pm 11.30$ & $3.08 \pm 7.55$ & $13.83 \pm 16.16$ \\
\hline $\mathrm{IL}-4$ & ND & ND & ND & $1.58 \pm 2.03$ \\
\hline MIP-1 $\alpha$ & ND & ND & ND & ND \\
\hline sIL-6R & $6836 \pm 980$ & $6123 \pm 442$ & $6282 \pm 320$ & $5620 \pm 800$ \\
\hline
\end{tabular}

Inflammatory mediators in the plasma of vehicle-, sgp130Fc-, and anti-IL-6 antibody-treated fractured and untreated nonfractured mice. Data are presented as the means \pm SD. $n=4$ to 6 .

IFN- $\gamma$, interferon- $\gamma$; MCP-1, monocyte chemotactic protein 1 ; MIP-1 $\alpha$, macrophage inflammatory protein- $1 \alpha$; ND, not detectable; sgp130Fc, soluble glycoprotein 130 fusion protein; sIL-6R, soluble IL-6 receptor; TNF- $\alpha$, tumor necrosis factor- $\alpha$. 
A

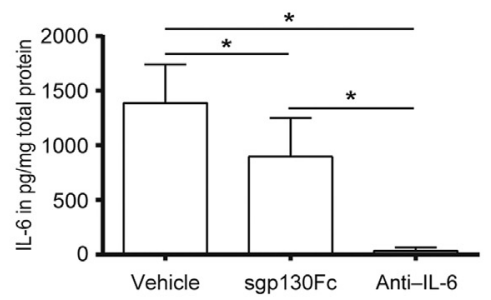

D

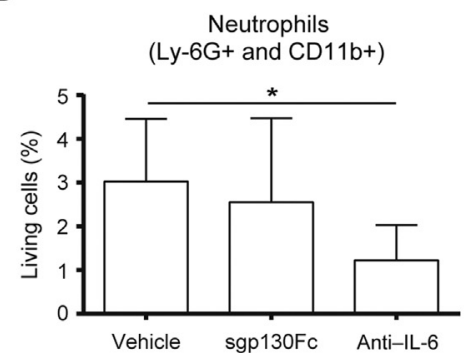

G

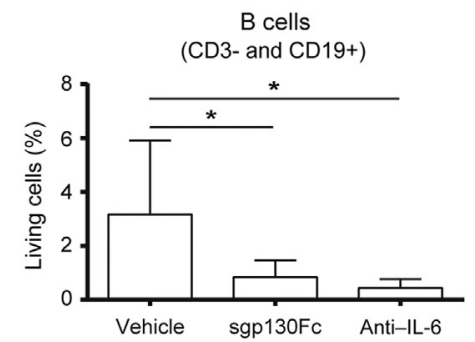

B

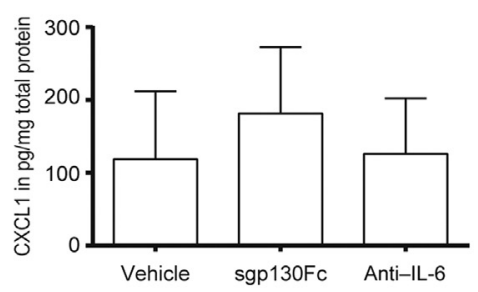

E

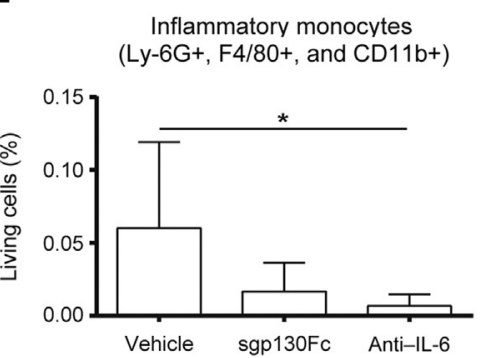

H

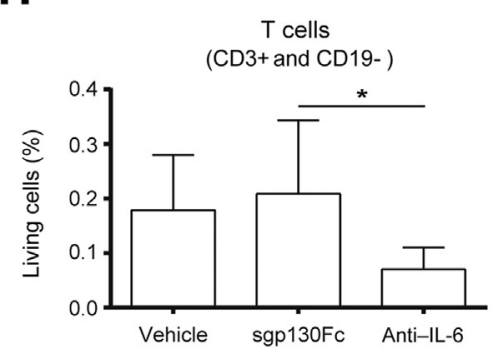

C

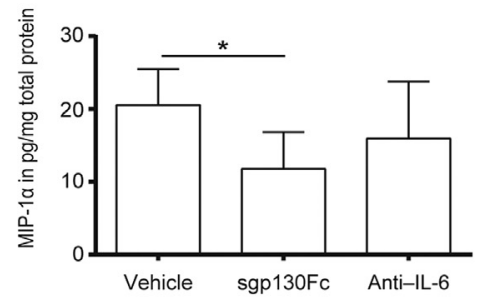

F

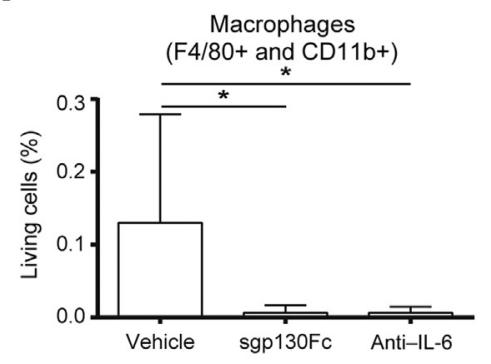

Figure 3 Inflammatory mediators and immune cells in the fracture hematoma on day 1. IL-6 (A), CXCL1 (B), and macrophage inflammatory protein-1 $\alpha$ (MIP$1 \alpha ; \mathbf{C})$ concentrations in the hematoma of vehicle-, soluble glycoprotein 130 fusion protein (sgp130Fc) - , and anti-IL- 6 antibody-treated mice 3 hours after fracture. Neutrophils $\left(\mathrm{Ly}_{-} 6 \mathrm{G}^{+}\right.$and $\left.\mathrm{CD} 11 \mathrm{~b}^{+} ; \mathbf{D}\right)$, inflammatory monocytes $\left(\mathrm{Ly}-6 \mathrm{G}^{+}, \mathrm{F} 4 / 80^{+}\right.$, and $\left.\mathrm{CD} 11 \mathrm{~b}^{+} ; \mathbf{E}\right)$, macrophages $\left(\mathrm{F} 4 / 80^{+}\right.$and $\left.\mathrm{CD} 11 \mathrm{~b}^{+} ; \mathrm{F}\right), \mathrm{B}$ cells $\left(\mathrm{CD} 3^{-}\right.$ and $\left.\mathrm{CD}_{19^{+}} ; \mathbf{G}\right)$, and T cells $\left(\mathrm{CD}^{+} \mathrm{CD}^{-} 9^{-} ; \mathbf{H}\right)$ in the fracture hematoma 1 day after fracture in vehicle-, sgp130Fc-, and anti-IL-6 antibody-treated mice, analyzed by flow cytometry. Data are expressed as means \pm SD. $n=6$ to $7(\mathbf{A}-\mathbf{H}) .{ }^{*} P<0.05$.

\section{Results}

IL-6 and IL-6R Are Expressed in the Fracture Callus in a Spatiotemporal Pattern

First, flow cytometry of the fracture hematoma on day 1 was performed to identify IL-6-producing and IL-6 target cells (Figure 1A). All investigated immune cells expressed IL-6 (Figure 1A). Inflammatory monocytes and B and T cells were strongly positive for mIL-6R, whereas neutrophils and macrophages were less stained (Figure 1A), indicating that inflammatory monocytes and $\mathrm{B}$ and $\mathrm{T}$ cells may be activated by IL-6 classic signaling at this time point. The gp130 was intensely expressed by all investigated immune cells, except neutrophils, which exhibited weak staining (Figure 1A). These results indicate that neutrophils might not only shed their IL-6R, but possibly also gp130. ${ }^{38,39}$ Confirming these data, inflammatory monocytes, $\mathrm{T}$ cells, and particularly $\mathrm{B}$ cells displayed strong pSTAT3 staining, whereas neutrophils and macrophages were less stained (Figure 1A).
Next, the expression of IL-6, mIL-6R, gp130, and pSTAT3 was analyzed at the fracture site at later time points by immunohistochemistry (Figure 1, B-U). On day 3, immune cells, which were located in the facture hematoma, and precursor cells, which were located in the proliferating periosteum, were strongly stained for IL-6, mIL-6R, gp130, and pSTAT3, indicating active IL-6 signaling in these cells (Figure 1, B, F, J, N, R, and V). On days 10 and 14, time points of extensive endochondral bone formation (Figure 1, $\mathrm{C}$ and D), proliferating chondroblasts (Figure 1, G and V), osteoblasts, and osteoclasts (Figure 1, H and V) were strongly positive for IL-6, whereas hypertrophic chondroblasts were rarely stained (Figure 1, G and V). mIL-6R was weakly expressed by chondroblasts (Figure 1, K and V), but intensely by osteoblasts and osteoclasts (Figure 1, L and V). All cells were positively stained for gp130 (Figure 1, O, P, and V). pSTAT3 was most intensely stained in osteoblasts but was also found in chondroblasts and osteoclasts (Figure 1, S, T, and V), indicating active STAT3 signaling. On day 21 , when most of the cartilage had been transformed 
Table 2 Cytokine and Chemokine Concentrations in Hematoma 3 Hours after Fracture

\begin{tabular}{|c|c|c|c|}
\hline \multirow{2}{*}{$\begin{array}{l}\text { Cytokine/ } \\
\text { chemokine }\end{array}$} & \multicolumn{3}{|c|}{$\begin{array}{l}\text { Hematoma concentration, } \mathrm{pg} / \mathrm{mg} \text { total protein } \\
\text { ( } 3 \text { hours after fracture) }\end{array}$} \\
\hline & Vehicle & sgp130Fc & Anti-IL-6 \\
\hline $\mathrm{IL}-1 \beta$ & $2.46 \pm 1.86$ & $3.65 \pm 1.58$ & $2.48 \pm 0.73$ \\
\hline TNF- $\alpha$ & ND & ND & ND \\
\hline MCP-1 & $369.95 \pm 143.69$ & $319.72 \pm 22.67$ & $282.99 \pm 186.16$ \\
\hline IFN- $\gamma$ & ND & ND & ND \\
\hline IL-10 & $4.17 \pm 8.29$ & $7.62 \pm 5.89$ & ND \\
\hline IL-13 & ND & ND & ND \\
\hline IL-4 & $5.10 \pm 3.18$ & $3.30 \pm 3.41$ & $5.78 \pm 3.48$ \\
\hline
\end{tabular}

Inflammatory mediators in the hematoma of vehicle-, sgp130Fc-, and antiIL- 6 antibody-treated mice. Data are expressed as means \pm SD. $n=6$ to 7 .

IFN- $\gamma$, interferon- $\gamma$; MCP-1, monocyte chemotactic protein 1 ; ND, not detectable; sgp130Fc, soluble glycoprotein 130 fusion protein; TNF- $\alpha$, tumor necrosis factor- $\alpha$.

to bone and the bony callus was being remodeled (Figure 1E), the strongest IL-6, mIL-6R, and gp130 staining was found in osteoblasts and osteoclasts (Figure 1, I, M, Q, and $\mathrm{V}$ ). The most intense pSTAT3 staining was found in the peripheral region of the fracture callus, where bone was most extensively remodeled (Figure 1, U and V).

To confirm the presence of the IL- 6 blockers at the fracture site, anti-IL-6 antibody and sgp $130 \mathrm{Fc}$, respectively, were immunestained on day 3. Anti-IL-6 antibody and sgp130Fc were mainly found in blood vessels around the fracture gap in mice treated with the respective inhibitor, whereas vehicle-treated control mice did not display any staining (Supplemental Figure S1A).

To exclude the effect of structure of the antibody itself on bone healing, the mice treated with phosphate-buffered saline or an IgG1 isotype antibody were compared. No significant differences, either in the recruitment of immune cells to the site of fracture on day 1 or in bone healing on day 21 (Supplemental Figure S1, B-I), were observed. Therefore, to reduce the number of mice used in this study, only phosphate-buffered saline-treated controls were used at the other time points investigated.

\section{Both IL-6 Signaling Pathways Differentially Regulate Inflammation after Fracture}

To assess the acute immune response, inflammatory mediators were measured in the circulation 3 hours after fracture. Compared with nonfractured mice, plasma levels of IL-6 and CXCL1 were significantly increased, indicating that the isolated fracture induced a systemic immune response (Figure 2, A and B). Other cytokines and chemokines were unaffected (Table 1). When the mice were treated with the anti-IL-6 antibody, the increase in IL-6 and CXCL1 plasma levels was almost completely abolished (Figure 2, A and B). Inhibition of IL-6 trans-signaling significantly reduced the fracture-induced increase of IL-6, whereas CXCL1 levels were not diminished (Figure 2, A and B). Because IL-6 is known to induce the release of acute-phase proteins from the liver, ${ }^{40}$ mRNA expression of CXCL1, CRP, and serum amyloid A was analyzed in liver homogenates 3 hours after fracture. The expression of all three mediators was increased in response to fracture and significantly reduced after global IL-6 inhibition, whereas the blockade of IL-6 trans-signaling had only minor effects (Figure 2, C-E). CRP plasma levels were also measured. After 3 hours, CRP plasma concentrations were not significantly affected in the treatment groups in comparison to untreated mice. However, after 24 hours, CRP was significantly increased by fracture. The increase was almost completely abolished in the anti-IL-6 antibody-treated mice in comparison to the vehicle- and sgp130Fc-treated animals (Supplemental Figure S2). These data indicate that the CRP release after fracture may be transcription dependent. In summary, these results confirm other studies reporting that hepatocytes are mainly activated by classic signaling via the mIL-6R. ${ }^{31}$ This was also corroborated by the evaluation of STAT3 activation in the liver (Figure 2F). The vehicle-treated mice displayed a strong STAT3 phosphorylation, indicating activation of intracellular IL-6 signaling. As expected, global IL-6 blockade almost completely abolished STAT3 phosphorylation in the liver, whereas the inhibition of IL-6 trans-signaling had a smaller effect in comparison to the global IL-6 inhibition (Figure 2F); however, it confirmed that both blocking strategies were principally effective.

The local immune response in the hematoma 3 hours after fracture was also assessed (Figure 3). Both blocking strategies significantly reduced IL-6 levels in the fracture hematoma in comparison to the vehicle-treated mice. Compared with anti-IL-6 antibody, the effect of the transsignaling inhibition was weaker, supporting the efficiency of the blocking strategy (Figure 3A). In contrast to the systemic levels, CXCL1 concentrations were unaffected within the hematoma (Figure 3B). Furthermore, the blockade of IL6 trans-signaling significantly reduced the macrophage inflammatory protein- $1 \alpha$ level, whereas other locally measured inflammatory mediators were not changed (Figure 3C and Table 2).

Flow cytometry analysis revealed that global IL-6 inhibition significantly reduced the proportion of all investigated immune cell populations in the fracture hematoma on day 1 (Figure 3, D-H). In contrast, inhibition of IL-6 transsignaling only significantly diminished macrophages (F4/ $80^{+}$and $\mathrm{CD} 11 \mathrm{~b}^{+}$) and $\mathrm{B}$ cells $\left(\mathrm{CD} 3^{-}\right.$and $\left.\mathrm{CD} 19^{+}\right)$, whereas the proportions of neutrophils $\left(\mathrm{Ly}-6 \mathrm{G}^{+}\right.$and $\mathrm{CD} 11 \mathrm{~b}^{+}$), inflammatory monocytes (Ly- $6 \mathrm{G}^{+}, \mathrm{F} 4 / 80^{+}$, and $\mathrm{CD} 11 \mathrm{~b}^{+}$), and $\mathrm{T}$ cells $\left(\mathrm{CD}^{+}\right.$and $\left.\mathrm{CD}^{-} 9^{-}\right)$were not significantly altered (Figure 3, D-H). Immunohistochemical staining on day 3 revealed that neutrophils $\left(\mathrm{Ly}-6 \mathrm{G}^{+}\right.$cells) were still reduced after global IL-6 inhibition, whereas blockade of IL-6 trans-signaling had no effect (Figure 4, A and D); 
A

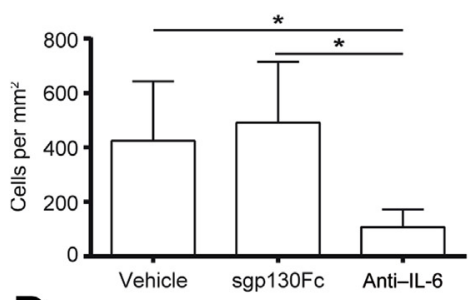

D

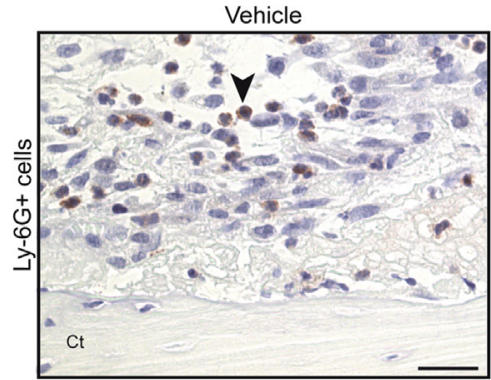

$\mathbf{E}$

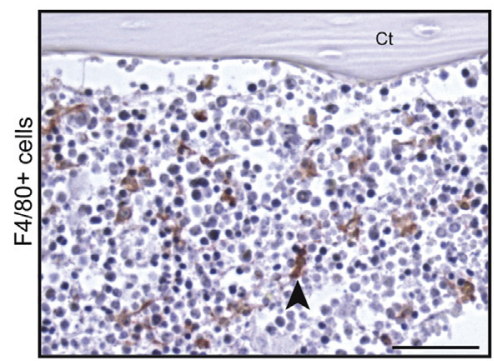

$\mathbf{F}$

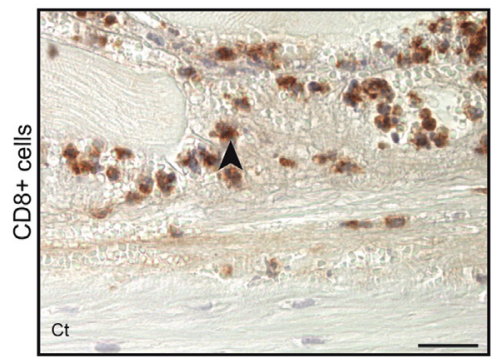

B

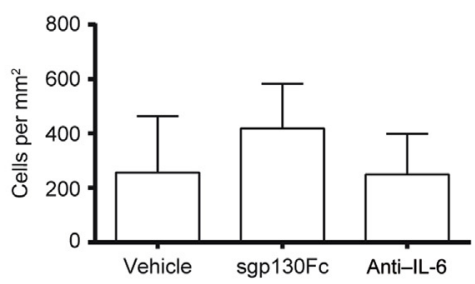

sgp130Fc
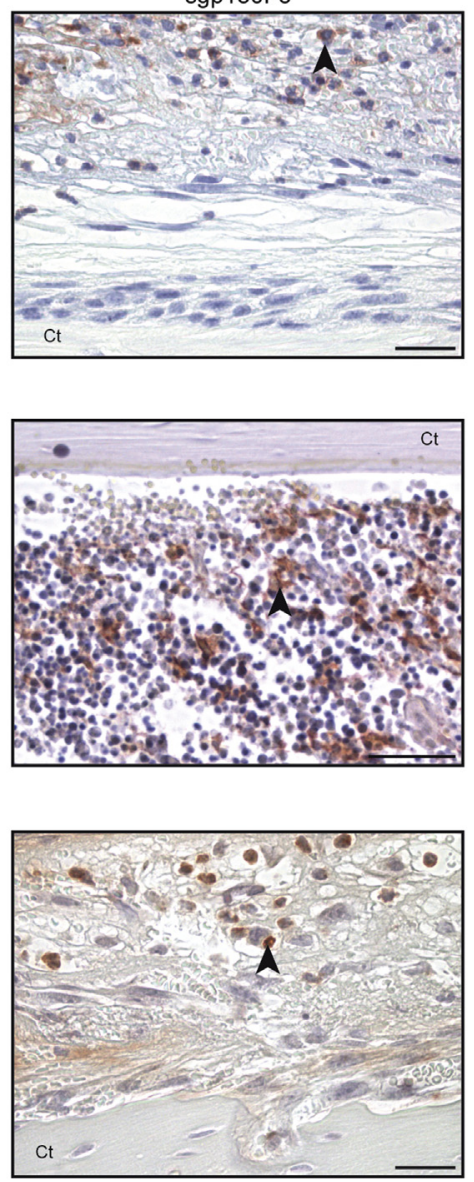

C
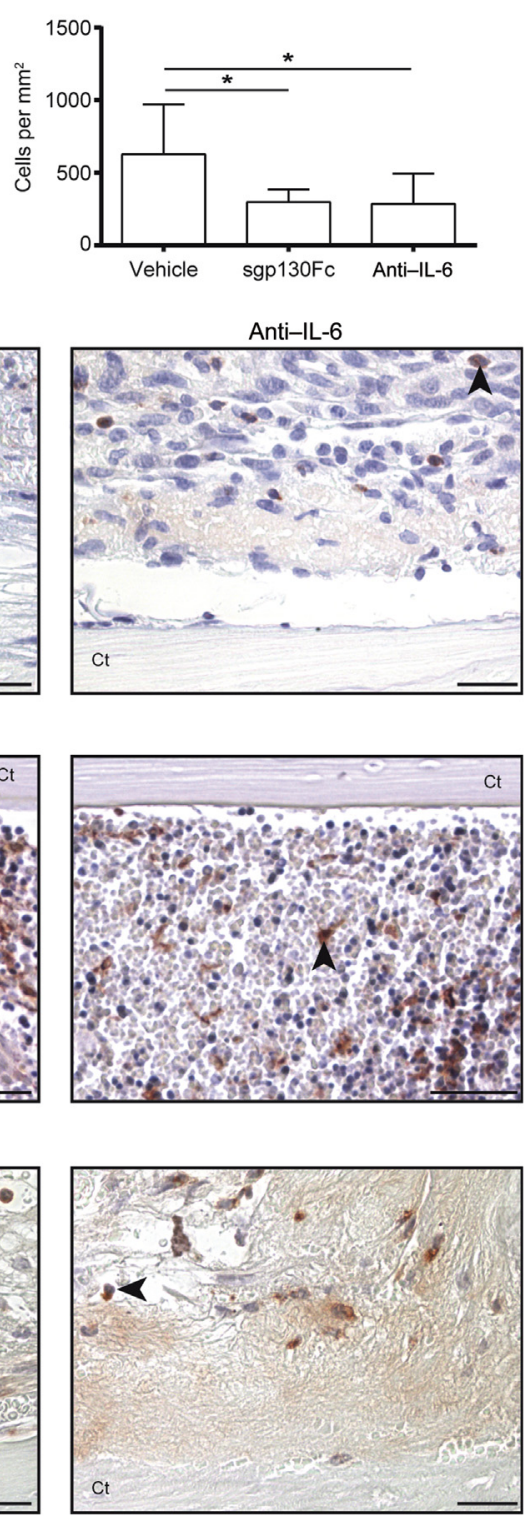

Figure 4 Immune cells in the fracture hematoma on day 3. Quantification of immunhistochemical staining of neutrophils $\left(\right.$ Ly- $\left.6 \mathrm{G}^{+} ; \mathbf{A}\right)$ in the periosteal callus, macrophages $\left(\mathrm{F} 4 / 80^{+} ; \mathbf{B}\right)$ in the marrow cavity, and cytotoxic $\mathrm{T}$ cells $\left(\mathrm{CD}^{+} ; \mathbf{C}\right)$ in the periosteal callus. Representative images of the fracture hematoma stained for neutrophils $\left(\mathrm{Ly}_{-} 6 \mathrm{G}^{+} ; \mathbf{D}\right)$, macrophages $\left(\mathrm{F} 4 / 80^{+} ; \mathbf{E}\right)$, and cytotoxic T cells $\left(\mathrm{CDB}^{+} ; \mathbf{F}\right)$. Arrowheads indicate some of the positively stained cells. Data are expressed as means \pm SD $(\mathbf{A}-\mathbf{C}) . n=5(\mathbf{A}-\mathbf{C})$. ${ }^{*} P<0.05$. Scale bars: $25 \mu \mathrm{m}(\mathbf{D}$ and $\mathbf{F}) ; 50 \mu \mathrm{m}(\mathbf{E})$. Original magnification: $\times 40(\mathbf{D}$ and $\mathbf{F}) ; \times 20(\mathbf{E}) . \mathbf{C t}$, cortex; sgp130Fc, soluble glycoprotein 130 fusion protein.

these findings confirmed the observations on day 1 and indicated that the presence of these cells may be mainly regulated via IL-6 classic signaling. Macrophages (F4/80 cells) were not affected in both treatment groups on day 3 (Figure 4, B and E), whereas the number of $\mathrm{CD} 8^{+} \mathrm{T}$ cells was diminished by both sgp130Fc and anti-IL-6 (Figure 4, $\mathrm{C}$ and $\mathrm{F}$ ). In conclusion, these results suggest that IL-6 classic and trans-signaling regulate immune cell recruitment and/or survival at the fracture site differentially and time dependently.
IL-6 Classic Signaling during the Inflammatory Phase Augments Subsequent Bone Formation

The effects of IL-6 inhibition during the early inflammatory phase on subsequent bone repair were investigated. Ten days after fracture, the inhibition of IL-6 trans-signaling did not affect tissue composition in the callus (Figure 5, A, B, and E); the osteoclastogenic mediator RANKL, which is strongly expressed by hypertrophic chondrocytes (Figure 5G); or the expression of the osteogenic differentiation marker 
runt-related transcription factor 2 in osteoblasts (Figure $5 \mathrm{H}$ ). In contrast, global inhibition of IL-6 signaling significantly reduced the bone fraction and increased the cartilage fraction in the callus, indicating delayed cartilage-to-bone transformation (Figure 5, A, B, and E). Accordingly, the osteoclast numbers (Figure 5, C and F) and RANKL expression (Figure 5G) were significantly reduced. In contrast, the number of osteoblasts and runt-related transcription factor 2 expression were unaffected, which may indicate undisturbed osteogenic differentiation (Figure 5, D and $\mathrm{H}$ ). The delay in bone healing after global IL-6 inhibition was also observable after 21 days. The fracture gap was poorly bridged, and the bending stiffness of the fracture callus was significantly reduced, after global IL-6 inhibition compared with vehicleor sgp130Fc-treated mice; however, the tissue fractions and cellular parameters in the callus were not significantly different (Figure 6). In summary, these data suggest that, during the early inflammatory phase, classic IL-6 signaling initiates processes that are crucial for subsequent endochondral ossification.

\section{IL-6 Classic Signaling during the Repair Phase Augments Endochondral Bone Formation and Remodeling}

To study IL-6 effects during callus formation, the IL-6 inhibitors were applied from day 7 onwards, after inflammation was terminated and bone was being formed by intramembranous and endochondral ossification. After 14 days, no differences were found between the treatment groups (Supplemental Figure S3). After 21 days, the blockade of IL-6 trans-signaling affected neither the callus composition nor its biomechanical properties (Figure 7). However, global IL-6 inhibition significantly increased the callus size (Figure 7C) and the bone and cartilage fractions (Figure 7, B, D, E, G), and reduced the osteoclast number, in the fracture callus (Figure 7F), suggesting delayed endochondral ossification and callus remodeling. The persisting callus explains the slightly enhanced bending stiffness (Figure 7, A and H). These results indicate that osteoclast activity during the repair and remodeling phase of fracture healing is regulated by classic IL-6 signaling.

\section{Discussion}

The present study elucidates the mechanistic differences between IL-6 classic and trans-signaling during bone fracture healing. The temporary global blockade of IL-6 during the early posttraumatic phase significantly reduced systemic inflammation, the hepatic acute-phase response, the recruitment of immune cells to the fracture site, and bone formation, finally resulting in delayed fracture healing. Global IL-6 inhibition during the later healing phase disturbed cartilage-to-bone transformation and bony callus remodeling. In contrast, selective inhibition of IL-6 transsignaling exerted only minor effects on the immune response and did not influence bone healing, suggesting that the classic pathway accounts for most of the observed effects after global IL-6 inhibition. Consequently, IL-6 classic signaling appears to be essential for a balanced immune response and undisturbed bone regeneration, whereas IL-6 trans-signaling does not seem to play a major role in uneventful fracture healing.

A well-established fracture mouse model, which induces a mild posttraumatic immune response, indicated by increased IL-6 serum levels, and allows uncomplicated secondary bone healing, ${ }^{32}$ was used. To discriminate IL-6 actions, a neutralizing anti-IL-6 antibody, which blocks IL-6 signaling globally, and the fusion protein sgp $130 \mathrm{Fc}$, an artificial fusion protein, which selectively binds the IL-6/sIL-6R complex and thus selectively inhibits IL-6 trans-signaling, ${ }^{28,30}$ were applied. Immunostaining confirmed that both compounds were present in the fracture callus after their respective systemic injection. In the liver, the anti-IL-6 antibody abolished fracture-induced STAT3 phosphorylation, whereas sgp130Fc displayed only minor effects compared with the anti-IL-6 antibody. Because hepatocytes express high levels of mIL-6R and can be activated by classic signaling, ${ }^{31}$ these results confirm the selectivity of the inhibitors at the concentrations used in the present study. ${ }^{41}$ Our results also confirmed previously published data ${ }^{3,42}$ reporting that IL-6 is expressed during the entire time course of fracture healing. In the present study, IL-6 was predominately expressed by immune cells during the inflammatory phase after fracture. Later, during bone repair, IL-6 was mainly produced by chondroblasts, osteoblasts, and osteoclasts, confirming that it plays a regulatory role in endochondral ossification. To detect the effector cells of IL-6, the presence of mIL-6R, gp130, and pSTAT3 was analyzed. Strong staining was found for mIL6R, gp130, and pSTAT3 in inflammatory monocytes and T and $\mathrm{B}$ cells during the inflammatory phase, indicating that these cells may be responsive for classic IL-6 signaling, as previously reported. ${ }^{25,43}$ Furthermore, it was shown that the STAT3 pathway was involved in the T-cell response during fracture healing, and its activation was associated with the patient's prognosis. ${ }^{44}$ In contrast, neutrophils were weakly stained for mIL-6R, gp130, and pSTAT3, suggesting that they had already shed the mIL-6R at the investigated time point. It is known that neutrophils are the main source for the sIL-6R under inflammatory conditions and might also shed gp130. ${ }^{38,39}$ In the later healing phases, mIL-6R, gp130, and pSTAT3 were also found in proliferating chondroblasts, osteoblasts, and osteoclasts. The most intense pSTAT3 staining was found in the peripheral region of the fracture callus after 21 days, when bone was most extensively remodeled, confirming the important role of IL-6 signaling in bone remodeling.

In the first part of the study, IL-6 signaling was temporarily inhibited during the early inflammatory phase after fracture to analyze its function in the immune response and in downstream effects on bone repair. Treatment with the anti-IL-6 antibody almost completely abolished the 
A

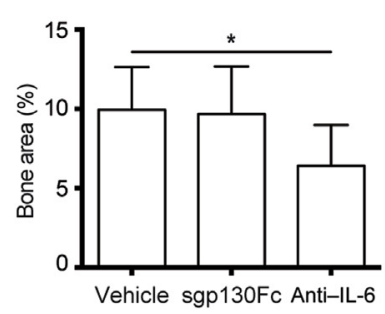

$\mathbf{E}$

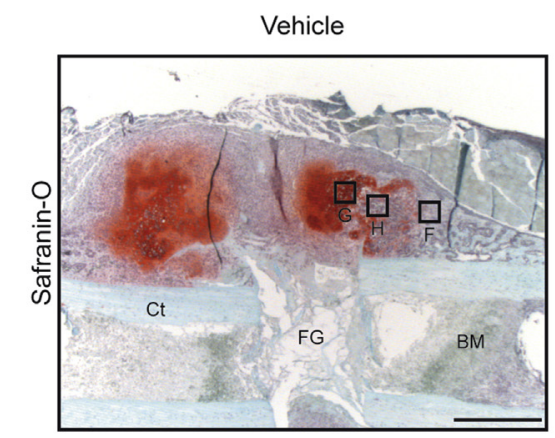

$\mathbf{F}$

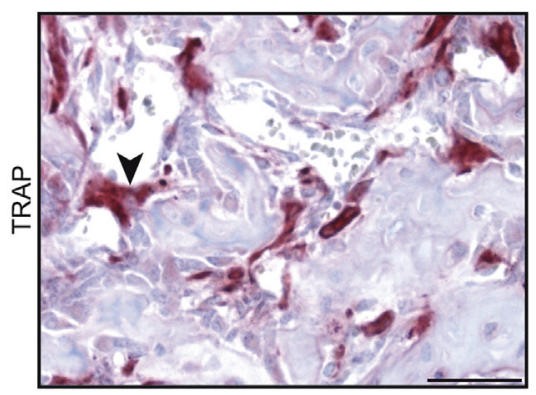

G

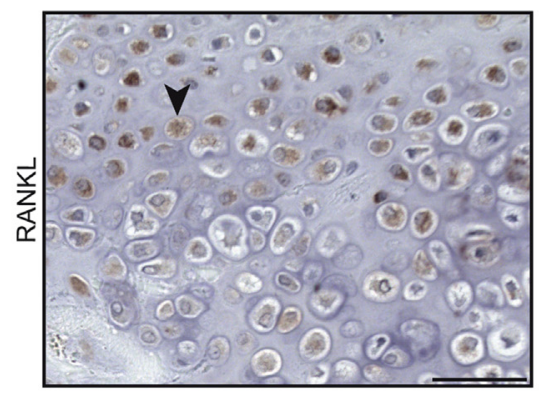

H

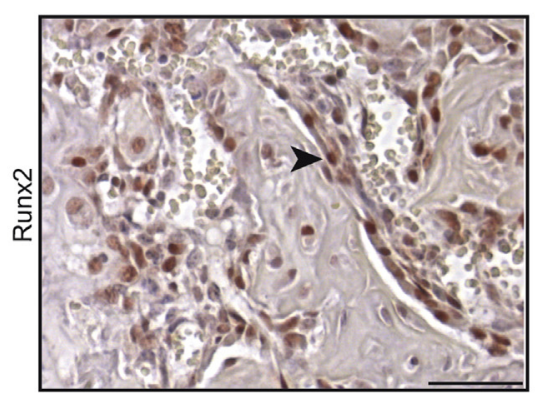

B C

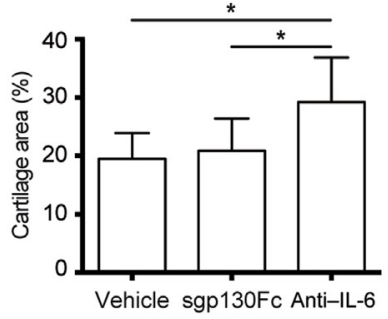

D

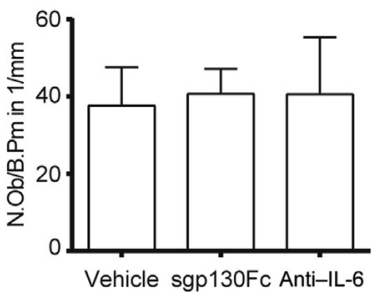

sgp130Fc
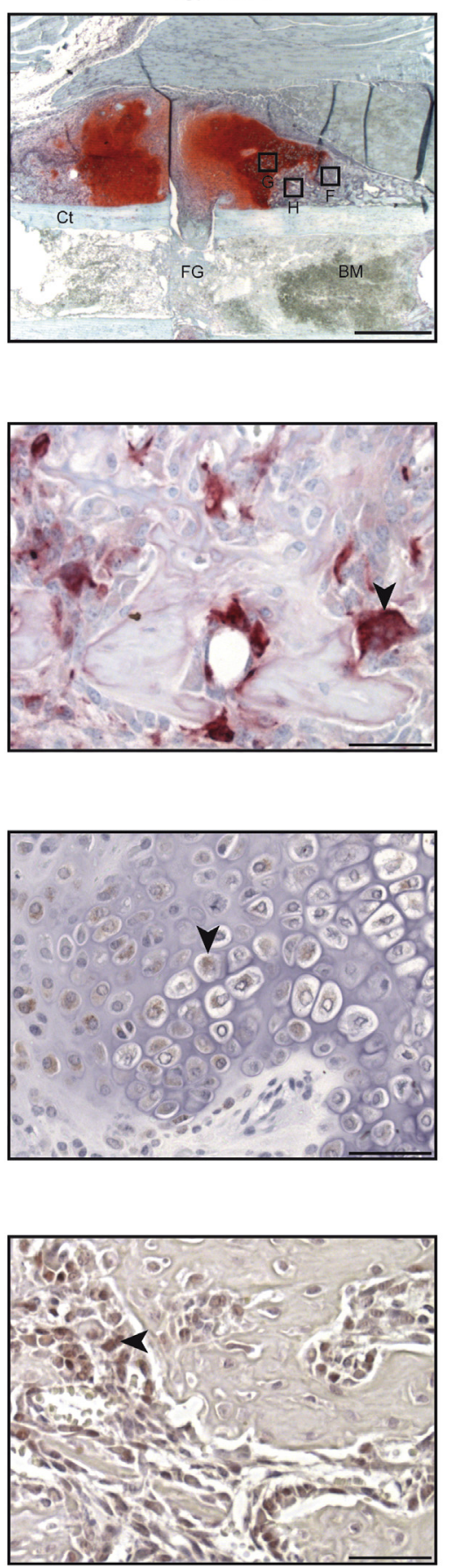

Anti-IL-6
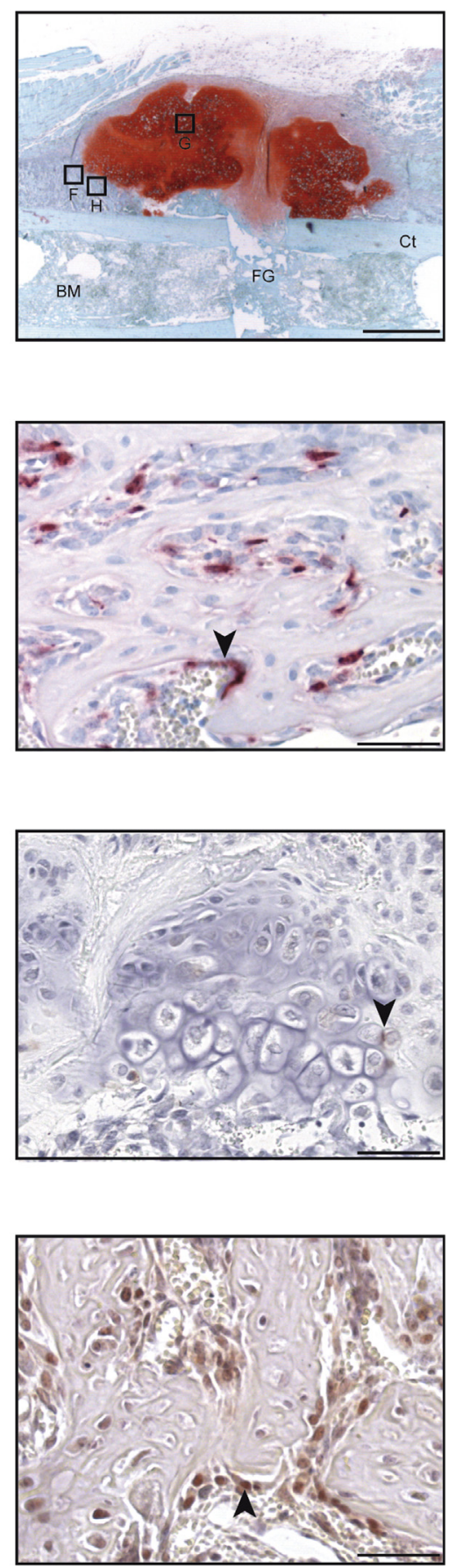
fracture-induced increase of circulating IL- 6 and reduced IL-6 concentrations within fracture hematoma. Comparably, sgp130Fc also significantly reduced plasma and local IL-6 concentrations, although less efficiently than the anti-IL-6 antibody. The most plausible explanation for this effect is that trapping of the IL-6/sIL-6R complex by sgp $130 \mathrm{Fc}$ favors the reestablishment of the initial equilibrium of IL-6/ sIL-6R complexes and, thus, indirectly reduces circulating free IL-6 molecules. ${ }^{41}$ Because classic signaling in hepatocytes is of crucial importance for the hepatic acute-phase response, ${ }^{31}$ CXCL1, CRP, and serum amyloid A expression levels were analyzed in the liver. Indeed, global IL-6 signaling inhibition reduced the acute-phase response, whereas the blockade of IL-6 trans-signaling had only minor effects. Hepatic IL-6 classic signaling is proposed to be crucial for the regenerative properties of IL-6, because it acts as a first-line defense against pathogens, thereby limiting inflammatory responses. ${ }^{31}$ Our results also indicate that, in addition to immune and endothelial cells, the liver may be an important source for the increased circulating CXCL1 after fracture, which was significantly reduced after global IL-6 signaling blockade, but not after selective transsignaling inhibition.

Locally in the fracture hematoma, IL-6 levels and the number of innate and adaptive immune cells within fracture hematoma were considerably reduced after global IL-6 inhibition; selective IL-6 trans-signaling inhibition had only minor effects, suggesting that IL-6 classic signaling crucially regulates immune cell recruitment to the fracture site in our model. It is proposed that IL-6 trans-signaling is responsible for an imbalanced immune cell recruitment, particularly under exaggerated inflammatory conditions. ${ }^{45}$ However, in the present study, a model of uncompromised bone healing was used, which is not associated with severe inflammation, and therefore, IL-6 trans-signaling may play a minor role. In detail, the number of neutrophils was found to be significantly diminished after global but not after trans-signaling inhibition. This may be explained by the decreased serum levels of CXCL1, which is a key chemoattractant for these cells. ${ }^{46}$ Neutrophils represent the most abundant cell population in the early fracture hematoma and appear to be of fundamental importance, because their depletion or dysfunction considerably disturbs bone repair. ${ }^{11,32,47}$ As the first line of defense, they clear cell debris and pathogens and attract monocytes and macrophages by secreting chemokines, including the monocyte chemoattractant macrophage inflammatory protein- $1 \alpha^{48}$ Similarly, macrophages remove pathogens and contribute to the termination of inflammation by polarizing to an antiinflammatory M2 phenotype, which secretes a broad spectrum of trophic factors, thus supporting angiogenesis and the recruitment of mesenchymal progenitors. ${ }^{49}$ Indeed, several studies demonstrated that macrophage recruitment and polarization are essential for undisturbed bone healing. ${ }^{50-52}$ In the present study, both blocking strategies reduced the number of macrophages at the fracture site, indicating that IL-6 trans-signaling may also be an important mechanism in attracting these cells. This finding is supported by a previous study reporting that IL-6 transsignaling was involved in the shift from a neutrophil to a mononuclear cell response. ${ }^{53}$ One day after fracture, the number of $\mathrm{CD}^{+} \mathrm{T}$ cells was significantly reduced after the application of anti-IL-6 antibody, but not after selective inhibition of IL-6 trans-signaling, suggesting that classic signaling may be important for T-cell recruitment in this context. In contrast, $\mathrm{CD} 8^{+}$cytotoxic $\mathrm{T}$ cells were reduced on day 3 after application of sgp $130 \mathrm{Fc}$, supporting the view that their recruitment might rather be influenced by IL- 6 trans-signaling, because $\mathrm{CD} 8^{+} \mathrm{T}$ cells express only low levels of mIL-6R. ${ }^{54}$ The number of B cells was significantly reduced after application of either IL- 6 inhibitor, and because mIL-6R is not expressed on all B-cell subtypes, ${ }^{20}$ their recruitment may be mainly regulated by transsignaling. Lymphocytes might play a crucial regulatory role in bone repair. In mice lacking both mature $\mathrm{T}$ and $\mathrm{B}$ cells through knockout of the recombination activating gene 1 $\left(R A G l^{-/-}\right)$, fracture healing was accelerated. ${ }^{55}$ However, the quality of the regenerated bone was inferior to that of wild-type mice. ${ }^{56}$ The depletion of $\mathrm{CD} 8^{+} \mathrm{T}$ cells resulted in enhanced fracture regeneration, whereas a transfer of these cells impaired the healing process, indicating a negative influence of $\mathrm{CD}^{+} \mathrm{T}$ cells on bone repair. ${ }^{57} \gamma \delta \mathrm{T}$ cells might also be negative for bone healing, because mice deficient for $\gamma \delta \mathrm{T}$ cells displayed decreased levels of inflammatory cytokines and improved healing. ${ }^{58}$ However, recently, a positive role for $\gamma \delta$ T-cell-derived IL-17A on bone regeneration was described. ${ }^{59}$ In addition, the loss of the regulatory function of $\mathrm{B}$ cells was associated with delayed healing in patients with bone fractures, ${ }^{60,61}$ and B cells were also suggested to modulate osteoclastogenesis ${ }^{62}$ and bone formation. ${ }^{63}$ Taken together, the role of lymphocytes in bone fracture healing appears to be complex and subtype

\footnotetext{
Figure 5 Inhibition of IL-6 signaling during the inflammatory phase of fracture healing: histomorphometric and immunohistochemical analyses of the fracture callus on day 10. A and B: Relative amount of bone $(\mathbf{A})$ and cartilage $(\mathbf{B})$ in the fracture callus determined by histomorphometric analyses in vehicle-, soluble glycoprotein 130 fusion protein (sgp130Fc)-, and anti-IL-6 antibody-treated mice. C and D: Number of osteoclasts per bone perimeter (N.0c/B.Pm; C) and number of osteoblasts per bone perimeter (N.Ob/B.Pm) in the fracture callus (D) are shown. $\mathbf{E}$ and $\mathbf{F}$ : Representative images of the fracture callus stained with Safranin-0 and tartrate-resistant acid phosphatase (TRAP). Boxed areas in $\mathbf{E}$ are shown at higher magnification in $\mathbf{F}-\mathbf{H}$. $\mathbf{G}$ and $\mathbf{H}$ : Representative images of receptor activator of NF- $\kappa B$ ligand (RANKL) - and runt-related transcription factor 2 (Runx2)-immunostained sections of the fracture callus. Arrowheads indicate some of the positively stained cells. Data are expressed as means \pm SD (A-D). $n=6(\mathbf{A}, \mathbf{B}$, and $\mathbf{D}) ; n=5$ to 6 (C). ${ }^{*} P<0.05$. Scale bars: $750 \mu \mathrm{m}$ (E and $\mathbf{F}$, Safranin-0 stain); $50 \mu \mathrm{m}$ (E and $\mathbf{F}$, TRAP stain, $\mathbf{G}$, and $\mathbf{H})$. Original magnification: $\times 12.5$ (E and $\mathbf{F}$, Safranin-0 stain); $\times 20$ (E and $\mathbf{F}$, TRAP stain, $\mathbf{G}$, and $\mathbf{H})$. BM, bone marrow; $\mathbf{C t}$, cortex; FG, fracture gap.
} 

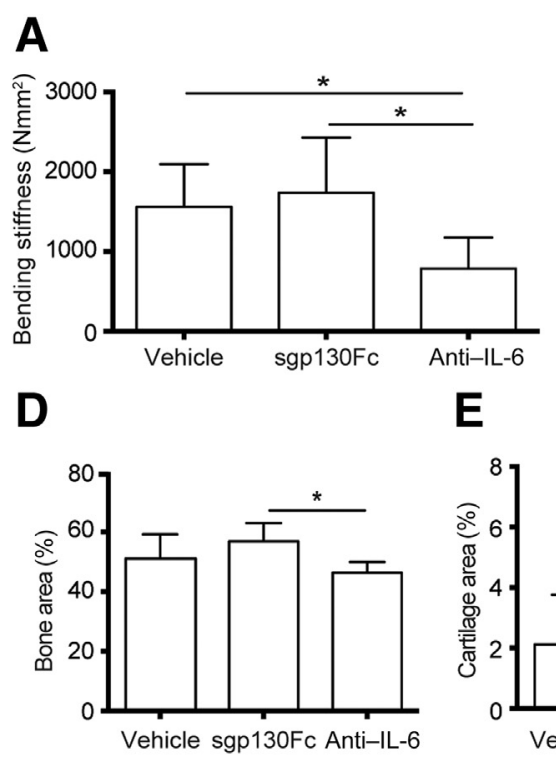

H

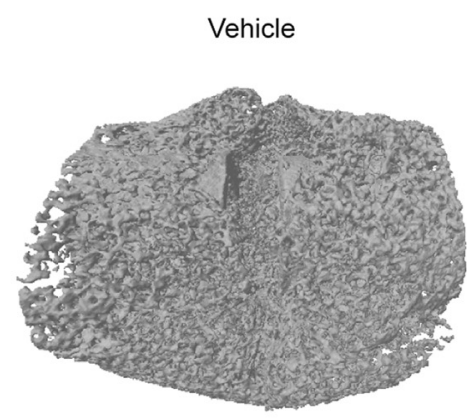

$87.5 \%$

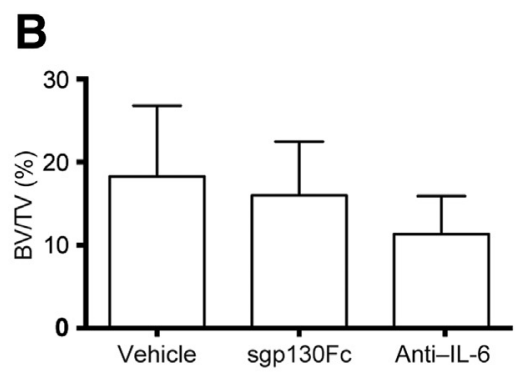

$\mathbf{F}$

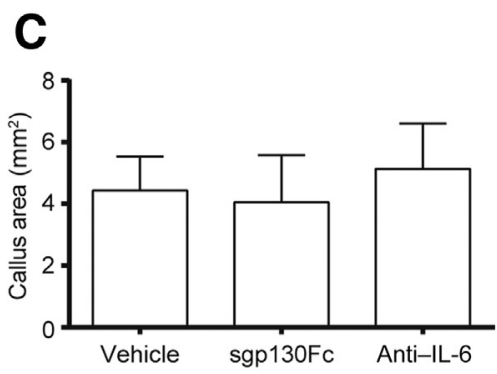

G
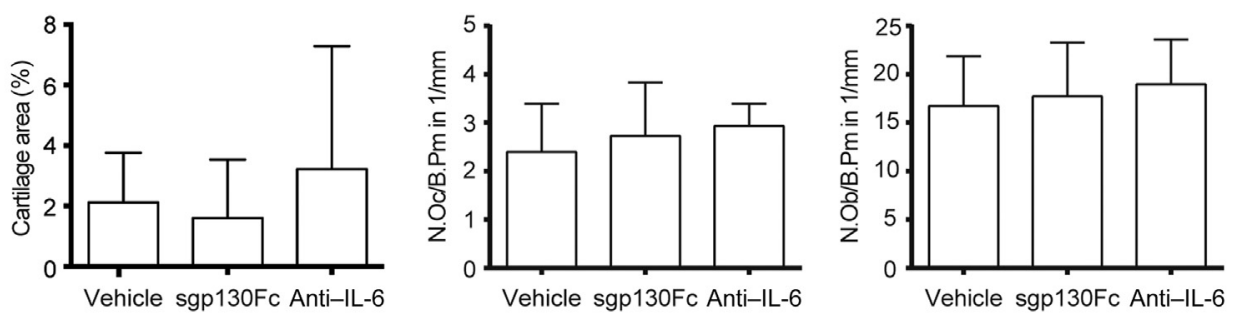

Healed fractures

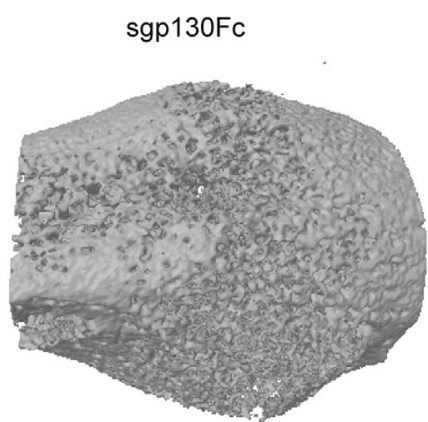

$87.5 \%$

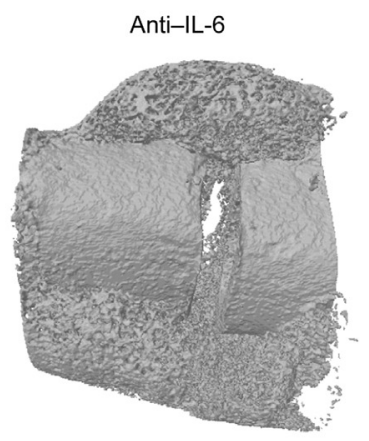

$33.3 \%$

Figure 6 Inhibition of IL-6 signaling during the inflammatory phase of fracture healing: histomorphometric and biomechanical analyses of the fracture callus on day 21. A: Bending stiffness of fractured femurs. B: Bone volume/total volume (BV/TV) of the fracture callus determined by micro-computed tomography $(\mu \mathrm{CT}) . \mathbf{C}-\mathbf{G}$ : Callus area $(\mathbf{C})$ and relative amount of bone $(\mathbf{D})$ and cartilage $(\mathbf{E})$ in the fracture callus determined by histomorphometric analyses. Number of osteoclasts per bone perimeter (N.OC/B.Pm; F) and number of osteoblasts per bone perimeter (N.Ob/B.Pm; G) in the fracture callus are shown. H: Representative three-dimensional reconstructions of the fracture callus and relative number of healed fractures analyzed by $\mu \mathrm{CT}$. Data are expressed as means \pm SD (A-G). $n=6$ to 8 (A and $\mathbf{B}) ; n=6$ to 7 (C-E and $\mathbf{G}) ; n=5$ to $6(\mathbf{F})$. ${ }^{*} P<0.05$. sgp130Fc, soluble glycoprotein 130 fusion protein.

dependent. Our results suggest that T cells may contribute to classic IL-6 signaling-mediated bone repair. However, further studies are needed to identify the involved T-cell subsets and underlying molecular mechanisms.

In summary, the short-term blockade of global IL-6 signaling during the early posttraumatic phase significantly reduced the systemic immune response, the production of acute-phase proteins in the liver, and the recruitment of immune cells to the fracture site, whereas selective inhibition of IL-6 trans-signaling exerted only minor effects. Taken together, this suggests that the classic IL-6 pathway is of key importance for a balanced immune response after fracture.

Our results also demonstrate that the immune response induced by classic IL-6 signaling after fracture is essential for subsequent bone repair. The early short-term blockade of global IL-6 signaling significantly reduced the bone fraction, but increased the cartilage fraction and the number of osteoclasts, in the fracture callus in the intermediate phase of fracture healing (day 10). The bending stiffness was significantly reduced in the late healing time phase (day 21), indicating poor callus quality. In contrast, the specific inhibition of IL-6 trans-signaling had no effects in this regard. The disturbed endochondral ossification observed after global IL-6 inhibition can be mainly explained by a reduced osteoclast formation. Both RANKL expression in hypertrophic chondrocytes and osteoclast numbers were significantly diminished. It cannot completely be excluded that this is attributable to direct effects of IL-6 inhibition on these cells, because osteoclast formation starts early after fracture ${ }^{64}$ and is known to be promoted by IL-6. ${ }^{65}$ However, we hypothesize that the impairment of endochondral bone formation might rather be caused by the impairment of the local immune response after global IL-6 inhibition. It has been shown that $\mathrm{T}$ cells, which were considerably 
A

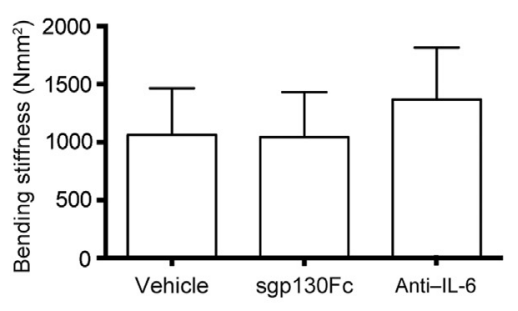

D

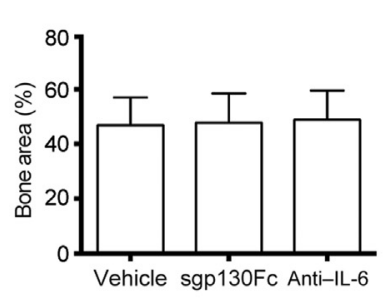

H

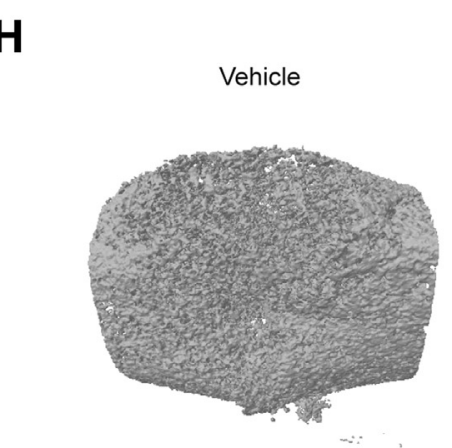

$100.0 \%$
B

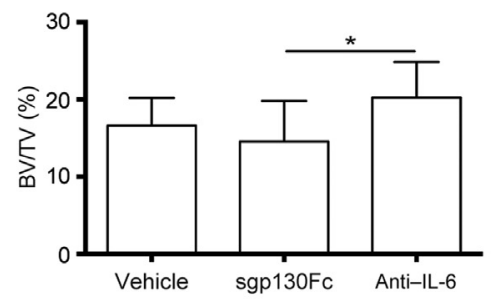

F
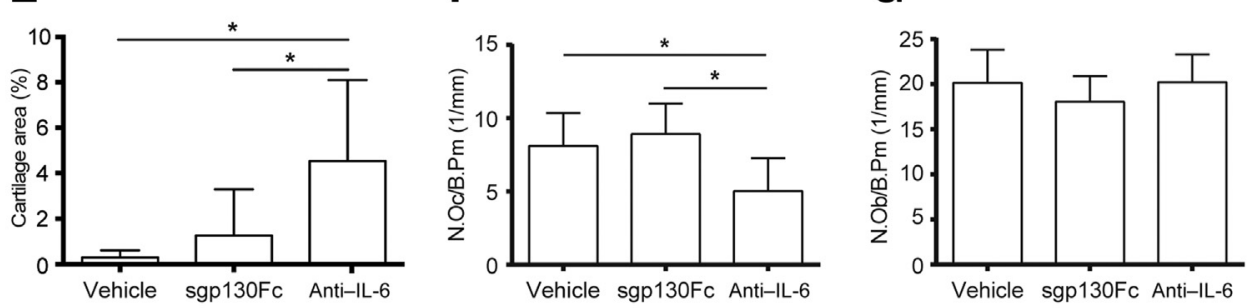

C

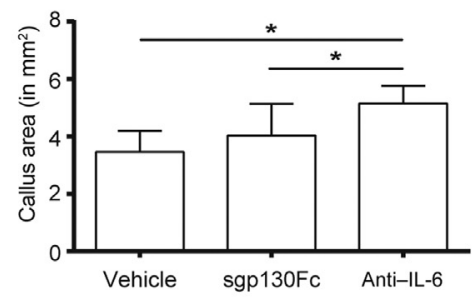

G
Healed fractures

sgp130Fc

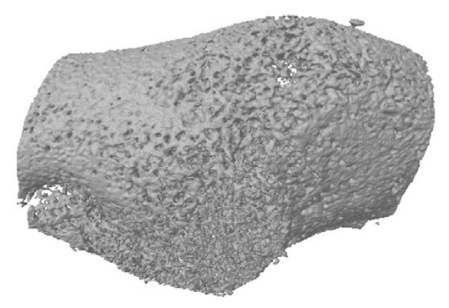

$100.0 \%$

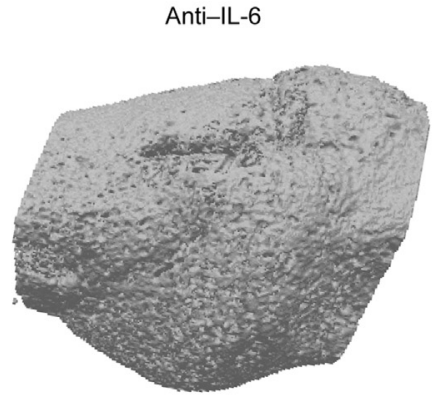

$83.3 \%$

Figure 7 Inhibition of IL-6 signaling during the repair phase of fracture healing: histomorphometric and biomechanical analyses of the fracture callus on day 21. A: Bending stiffness of fractured femurs. B: Bone volume/total volume (BV/TV) of the fracture callus determined by micro-computed tomography $(\mu \mathrm{CT}) . \mathbf{C}-\mathbf{G}$ : Callus area $(\mathbf{C})$ and relative amount of bone $(\mathbf{D})$ and cartilage $(\mathbf{E})$ in the fracture callus determined by histomorphometric analyses. Number of osteoclasts per bone perimeter (N.0c/B.Pm; F) and number of osteoblasts per bone perimeter (N.Ob/B.Pm; G) in the fracture callus are shown. H: Representative three-dimensional reconstructions of the fracture callus and relative number of healed fractures analyzed by $\mu \mathrm{CT}$. Data are expressed as means \pm SD $(\mathbf{A}-\mathbf{G}) . n=6(\mathbf{A}-\mathbf{E}$ and $\mathbf{G}) ; n=5$ to $6(\mathbf{F}) .{ }^{*} P<0.05$. sgp130Fc, soluble glycoprotein 130 fusion protein.

diminished after global IL-6 inhibition, support osteoclast formation via RANKL-dependent and RANKL-independent mechanisms. ${ }^{66}$ Taken together, our results suggest that IL-6 classic signaling in the inflammatory phase may induce downstream processes that augment bone repair, but the exact mechanisms remain to be elucidated.

In the second part of our study, the role of IL-6 classic and trans-signaling was investigated during the bone repair phase. The IL-6 inhibitors were applied only from day 7 onwards, this being after the end of the acute inflammatory phase. After global IL-6 inhibition, an increased bone fraction, persisting cartilage, and a reduced osteoclast number were observed, confirming the results of studies using IL-6 knockout mice. ${ }^{16,17}$ In contrast, the specific inhibition of IL-6 trans-signaling had no effects. This suggests that IL-6 classic signaling via the $\mathrm{mIL}-6 \mathrm{R}$ is of crucial importance for cartilage-to-bone transformation and callus remodeling by controlling osteoclast activity. Accordingly, both osteoblasts and osteoclasts in the fracture callus did not only produce IL-6, but also strongly expressed the mIL-6R. These findings are in agreement with other studies showing that osteoclasts express the mIL-6R. ${ }^{24,67}$ Although IL-6 alone directly inhibited osteoclast formation from precursor cells in vitro, ${ }^{68}$ it was also shown that IL-6 can directly increase osteoclast formation by a RANKLindependent mechanism. ${ }^{69}$ In osteoblasts, the expression level of mIL-6R was described to be low or even absent, suggesting that osteoblasts might be mainly responsive to IL-6 trans-signaling, which stimulates osteoblast proliferation and differentiation. ${ }^{70,71}$ However, in our study, strong staining for mIL-6R and pSTAT3 was observed in osteoblasts, indicating that classic signaling may regulate these cells during bone repair. In conclusion, our results show that both osteoblasts and osteoclasts secrete IL-6 during bone formation and callus remodeling and may be activated by classic IL- 6 signaling in an autocrine or paracrine manner, because they express high levels of the membrane-bound IL-6R. 


\section{Conclusions}

In summary, the present study demonstrates that IL- 6 classic signaling is of crucial importance to induce a balanced immune response after fracture and to induce regenerative downstream processes leading to bone repair. In the later healing phase, classic signaling regulates cartilage-to-bone transformation and callus remodeling. This may be clinically relevant for bone fractures in patients with rheumatoid arthritis undergoing anti-IL-6 or anti-IL-6R therapy, because bone healing may be impaired. In contrast, IL-6 trans-signaling plays only a minor role, at least in the model of uneventful fracture healing used in the present study. Because IL-6 trans-signaling is proposed to account for many deleterious effects of IL- $6,{ }^{25}$ in our ongoing studies we are investigating whether IL-6 trans-signaling is involved in the pathomechanisms of compromised bone healing in patients with inflammatory disorders.

\section{Acknowledgments}

We thank Iris Baum, Sevil Essig, Uschi Maile, Stefanie Schroth, Chérise Grieser, and Marion Tomo for technical assistance; and Naveen Tangudu for help with the multiplex immunoassay.

A.K., G.H.W., S.R.-J., and A.I. designed the study; K.P. and K.K. conducted experiments; G.S., G.H.W., S.R.-J., and A.I. provided resources; K.P., K.K., and V.F. collected data. K.P. and K.K. analyzed data; K.P., K.K., A.K., M.H.-L., A.R., A.L., S.R.-J., and A.I. interpreted data; K.P., A.K., M.H.-L., and A.I. wrote the manuscript; K.P., K.K., A.K., M.H.-L, V.F., A.R., A.L., G.S., G.H.W., S.R.-J., and A.I. revised the manuscript; K.P., K.K., A.K., M.H.-L., V.F., A.R., A.L., G.S., G.H.W., S.R.-J., and A.I. approved the final version of the manuscript; K.P. takes responsibility for the integrity of the data analysis.

\section{Supplemental Data}

Supplemental material for this article can be found at https://doi.org/10.1016/j.ajpath.2017.10.011.

\section{References}

1. Claes L, Recknagel S, Ignatius A: Fracture healing under healthy and inflammatory conditions. Nat Rev Rheumatol 2012, 8:133-143

2. Loi F, Cordova LA, Pajarinen J, Lin TH, Yao Z, Goodman SB: Inflammation, fracture and bone repair. Bone 2016, 86:119-130

3. Ai-Aql ZS, Alagl AS, Graves DT, Gerstenfeld LC, Einhorn TA: Molecular mechanisms controlling bone formation during fracture healing and distraction osteogenesis. J Dent Res 2008, 87:107-118

4. Einhorn TA, Gerstenfeld LC: Fracture healing: mechanisms and interventions. Nat Rev Rheumatol 2015, 11:45-54

5. Hardy R, Cooper MS: Bone loss in inflammatory disorders. J Endocrinol 2009, 201:309-320

6. Edwards CJ, Williams E: The role of interleukin-6 in rheumatoid arthritis-associated osteoporosis. Osteoporos Int 2010, 21:1287-1293
7. Oei L, Rivadeneira F, Zillikens MC, Oei EH: Diabetes, diabetic complications, and fracture risk. Curr Osteoporos Rep 2015, 13:106-115

8. Gebhard F, Pfetsch H, Steinbach G, Strecker W, Kinzl L, Bruckner UB: Is interleukin 6 an early marker of injury severity following major trauma in humans? Arch Surg 2000, 135:291-295

9. Karladani AH, Granhed H, Karrholm J, Styf J: The influence of fracture etiology and type on fracture healing: a review of 104 consecutive tibial shaft fractures. Arch Orthop Trauma Surg 2001, 121:325-328

10. Bhandari M, Tornetta P 3rd, Sprague S, Najibi S, Petrisor B, Griffith L, Guyatt GH: Predictors of reoperation following operative management of fractures of the tibial shaft. J Orthop Trauma 2003, 17:353-361

11. Recknagel S, Bindl R, Brochhausen C, Göckelmann M, Wehner T, Schoengraf P, Huber-Lang M, Claes L, Ignatius A: Systemic inflammation induced by a thoracic trauma alters the cellular composition of the early fracture callus. J Trauma Acute Care Surg 2013, 74:531-537

12. Hoff P, Gaber T, Strehl C, Jakstadt M, Hoff H, Schmidt-Bleek K, Lang A, Rohner E, Huscher D, Matziolis G, Burmester GR, Schmidmaier G, Perka C, Duda GN, Buttgereit F: A pronounced inflammatory activity characterizes the early fracture healing phase in immunologically restricted patients. Int J Mol Sci 2017, 18:E583

13. Blanchard F, Duplomb L, Baud'huin M, Brounais B: The dual role of IL-6-type cytokines on bone remodeling and bone tumors. Cytokine Growth Factor Rev 2009, 20:19-28

14. Kon T, Cho TJ, Aizawa T, Yamazaki M, Nooh N, Graves D, Gerstenfeld LC, Einhorn TA: Expression of osteoprotegerin, receptor activator of NF-kappaB ligand (osteoprotegerin ligand) and related proinflammatory cytokines during fracture healing. J Bone Miner Res 2001, 16:1004-1014

15. Cho TJ, Kim JA, Chung CY, Yoo WJ, Gerstenfeld LC, Einhorn TA, Choi IH: Expression and role of interleukin-6 in distraction osteogenesis. Calcif Tissue Int 2007, 80:192-200

16. Yang X, Ricciardi BF, Hernandez-Soria A, Shi Y, Pleshko Camacho N, Bostrom MP: Callus mineralization and maturation are delayed during fracture healing in interleukin-6 knockout mice. Bone 2007, 41:928-936

17. Wallace A, Cooney TE, Englund R, Lubahn JD: Effects of interleukin-6 ablation on fracture healing in mice. J Orthop Res 2011, 29:1437-1442

18. Wallenius V, Wallenius $\mathrm{K}$, Ahren B, Rudling $\mathrm{M}$, Carlsten $\mathrm{H}$, Dickson SL, Ohlsson C, Jansson JO: Interleukin-6-deficient mice develop mature-onset obesity. Nat Med 2002, 8:75-79

19. Braida D, Sacerdote P, Panerai AE, Bianchi M, Aloisi AM, Iosue S, Sala M: Cognitive function in young and adult IL (interleukin)-6 deficient mice. Behav Brain Res 2004, 153:423-429

20. Hoge J, Yan I, Janner N, Schumacher V, Chalaris A, Steinmetz OM, Engel DR, Scheller J, Rose-John S, Mittrucker HW: IL-6 controls the innate immune response against Listeria monocytogenes via classical IL-6 signaling. J Immunol 2013, 190:703-711

21. Pazos P, Lima L, Casanueva FF, Dieguez C, Garcia MC: Interleukin 6 deficiency modulates the hypothalamic expression of energy balance regulating peptides during pregnancy in mice. PLoS One 2013, 8:e72339

22. Aniszewska A, Szymanski J, Winnicka MM, Turlejski K: Interleukin 6 deficiency affects spontaneous activity of mice in age- and sexdependent manner. Acta Neurobiol Exp (Wars) 2014, 74:424-432

23. Heinrich PC, Behrmann I, Haan S, Hermanns HM, Muller-Newen G, Schaper F: Principles of interleukin (IL)-6-type cytokine signalling and its regulation. Biochem J 2003, 374:1-20

24. Sims NA, Walsh NC: GP130 cytokines and bone remodelling in health and disease. BMB Rep 2010, 43:513-523

25. Rose-John S: IL-6 trans-signaling via the soluble IL-6 receptor: importance for the pro-inflammatory activities of IL-6. Int J Biol Sci 2012, 8:1237-1247

26. Lokau J, Agthe M, Garbers C: Generation of soluble interleukin-11 and interleukin-6 receptors: a crucial function for proteases during inflammation. Mediators Inflamm 2016, 2016:1785021 
27. Morieri ML, Passaro A, Zuliani G: Interleukin-6 "trans-signaling" and ischemic vascular disease: the important role of soluble gp130. Mediators Inflamm 2017, 2017:1396398

28. Rose-John S, Waetzig GH, Scheller J, Grotzinger J, Seegert D: The IL-6/sIL-6R complex as a novel target for therapeutic approaches. Expert Opin Ther Targets 2007, 11:613-624

29. Röntgen V, Blakytny R, Matthys R, Landauer M, Wehner T, Gockelmann M, Jermendy P, Amling M, Schinke T, Claes L, Ignatius A: Fracture healing in mice under controlled rigid and flexible conditions using an adjustable external fixator. J Orthop Res 2010, 28:1456-1462

30. Barkhausen $\mathrm{T}$, Tschernig $\mathrm{T}$, Rosenstiel $\mathrm{P}$, van Griensven M, Vonberg RP, Dorsch M, Mueller-Heine A, Chalaris A, Scheller J, Rose-John S, Seegert D, Krettek C, Waetzig GH: Selective blockade of interleukin-6 trans-signaling improves survival in a murine polymicrobial sepsis model. Crit Care Med 2011, 39:1407-1413

31. Schmidt-Arras D, Rose-John S: IL-6 pathway in the liver: from physiopathology to therapy. J Hepatol 2016, 64:1403-1415

32. Kovtun A, Bergdolt S, Wiegner R, Radermacher P, Huber-Lang M, Ignatius A: The crucial role of neutrophil granulocytes in bone fracture healing. Eur Cell Mater 2016, 32:152-162

33. Ramakers C, Ruijter JM, Deprez RH, Moorman AF: Assumption-free analysis of quantitative real-time polymerase chain reaction (PCR) data. Neurosci Lett 2003, 339:62-66

34. Dempster DW, Compston JE, Drezner MK, Glorieux FH, Kanis JA, Malluche H, Meunier PJ, Ott SM, Recker RR, Parfitt AM: Standardized nomenclature, symbols, and units for bone histomorphometry: a 2012 update of the report of the ASBMR Histomorphometry Nomenclature Committee. J Bone Miner Res 2013, 28:2-17

35. Haffner-Luntzer M, Heilmann A, Rapp AE, Roessler R, Schinke T, Amling M, Ignatius A, Liedert A: Antagonizing midkine accelerates fracture healing in mice by enhanced bone formation in the fracture callus. Br J Pharmacol 2016, 173:2237-2249

36. Morgan EF, Mason ZD, Chien KB, Pfeiffer AJ, Barnes GL, Einhorn TA, Gerstenfeld LC: Micro-computed tomography assessment of fracture healing: relationships among callus structure, composition, and mechanical function. Bone 2009, 44:335-344

37. Bouxsein ML, Boyd SK, Christiansen BA, Guldberg RE, Jepsen KJ, Muller R: Guidelines for assessment of bone microstructure in rodents using micro-computed tomography. J Bone Miner Res 2010, $25: 1468-1486$

38. Chalaris A, Rabe B, Paliga K, Lange H, Laskay T, Fielding CA, Jones SA, Rose-John S, Scheller J: Apoptosis is a natural stimulus of IL6R shedding and contributes to the proinflammatory trans-signaling function of neutrophils. Blood 2007, 110:1748-1755

39. Wolf J, Waetzig GH, Chalaris A, Reinheimer TM, Wege H, RoseJohn S, Garbers C: Different soluble forms of the interleukin-6 family signal transducer gp130 fine-tune the blockade of interleukin- 6 transsignaling. J Biol Chem 2016, 291:16186-16196

40. Sander LE, Sackett SD, Dierssen U, Beraza N, Linke RP, Muller M, Blander JM, Tacke F, Trautwein C: Hepatic acute-phase proteins control innate immune responses during infection by promoting myeloidderived suppressor cell function. J Exp Med 2010, 207:1453-1464

41. Garbers C, Thaiss W, Jones GW, Waetzig GH, Lorenzen I, Guilhot F, Lissilaa R, Ferlin WG, Grotzinger J, Jones SA, Rose-John S, Scheller J: Inhibition of classic signaling is a novel function of soluble glycoprotein 130 (sgp130), which is controlled by the ratio of interleukin 6 and soluble interleukin 6 receptor. J Biol Chem 2011, 286:42959-42970

42. Gerstenfeld LC, Cullinane DM, Barnes GL, Graves DT, Einhorn TA: Fracture healing as a post-natal developmental process: molecular, spatial, and temporal aspects of its regulation. J Cell Biochem 2003, $88: 873-884$

43. Schumacher N, Meyer D, Mauermann A, von der Heyde J, Wolf J, Schwarz J, Knittler K, Murphy G, Michalek M, Garbers C, Bartsch JW, Guo S, Schacher B, Eickholz P, Chalaris A, Rose-John S, Rabe B:
Shedding of endogenous interleukin-6 receptor (IL-6R) is governed by a disintegrin and metalloproteinase (ADAM) proteases while a fulllength IL-6R isoform localizes to circulating microvesicles. J Biol Chem 2015, 290:26059-26071

44. Sun G, Wang Z, Ti Y, Wang Y, Wang J, Zhao J, Qian H: STAT3 promotes bone fracture healing by enhancing the FOXP3 expression and the suppressive function of regulatory T cells. APMIS 2017, 125: $752-760$

45. Waetzig GH, Rose-John S: Hitting a complex target: an update on interleukin-6 trans-signalling. Expert Opin Ther Targets 2012, 16: 225-236

46. Sawant KV, Poluri KM, Dutta AK, Sepuru KM, Troshkina A, Garofalo RP, Rajarathnam K: Chemokine CXCL1 mediated neutrophil recruitment: role of glycosaminoglycan interactions. Sci Rep 2016, 6:33123

47. Bastian OW, Koenderman L, Alblas J, Leenen LP, Blokhuis TJ: Neutrophils contribute to fracture healing by synthesizing fibronectin + extracellular matrix rapidly after injury. Clin Immunol 2016, 164:78-84

48. Soehnlein O, Lindbom L, Weber C: Mechanisms underlying neutrophil-mediated monocyte recruitment. Blood 2009, 114: $4613-4623$

49. Sinder BP, Pettit AR, McCauley LK: Macrophages: their emerging roles in bone. J Bone Miner Res 2015, 30:2140-2149

50. Raggatt LJ, Wullschleger ME, Alexander KA, Wu AC, Millard SM, Kaur S, Maugham ML, Gregory LS, Steck R, Pettit AR: Fracture healing via periosteal callus formation requires macrophages for both initiation and progression of early endochondral ossification. Am J Pathol 2014, 184:3192-3204

51. Lu LY, Loi F, Nathan K, Lin TH, Pajarinen J, Gibon E, Nabeshima A, Cordova L, Jamsen E, Yao Z, Goodman SB: Proinflammatory M1 macrophages promote osteogenesis by mesenchymal stem cells via the COX-2-prostaglandin E2 pathway. J Orthop Res 2017, 35:2378-2385

52. Sandberg OH, Tatting L, Bernhardsson ME, Aspenberg P: Temporal role of macrophages in cancellous bone healing. Bone 2017, 101: $129-133$

53. Rabe B, Chalaris A, May U, Waetzig GH, Seegert D, Williams AS, Jones SA, Rose-John S, Scheller J: Transgenic blockade of interleukin 6 transsignaling abrogates inflammation. Blood 2008, 111: $1021-1028$

54. Bottcher JP, Schanz O, Garbers C, Zaremba A, Hegenbarth S, Kurts C, Beyer M, Schultze JL, Kastenmuller W, Rose-John S, Knolle PA: IL-6 trans-signaling-dependent rapid development of cytotoxic CD8+ T cell function. Cell Rep 2014, 8:1318-1327

55. Toben D, Schroeder I, El Khassawna T, Mehta M, Hoffmann JE, Frisch JT, Schell H, Lienau J, Serra A, Radbruch A, Duda GN: Fracture healing is accelerated in the absence of the adaptive immune system. J Bone Miner Res 2011, 26:113-124

56. El Khassawna T, Serra A, Bucher CH, Petersen A, Schlundt C, Konnecke I, Malhan D, Wendler S, Schell H, Volk HD, SchmidtBleek K, Duda GN: T lymphocytes influence the mineralization process of bone. Front Immunol 2017, 8:562

57. Reinke S, Geissler S, Taylor WR, Schmidt-Bleek K, Juelke K, Schwachmeyer V, Dahne M, Hartwig T, Akyuz L, Meisel C, Unterwalder N, Singh NB, Reinke P, Haas NP, Volk HD, Duda GN: Terminally differentiated CD8(+) $\mathrm{T}$ cells negatively affect bone regeneration in humans. Sci Transl Med 2013, 5:177ra136

58. Colburn NT, Zaal KJ, Wang F, Tuan RS: A role for gamma/delta T cells in a mouse model of fracture healing. Arthritis Rheum 2009, 60: 1694-1703

59. Ono T, Okamoto K, Nakashima T, Nitta T, Hori S, Iwakura Y, Takayanagi H: IL-17-producing gammadelta $\mathrm{T}$ cells enhance bone regeneration. Nat Commun 2016, 7:10928

60. Yang S, Ding W, Feng D, Gong H, Zhu D, Chen B, Chen J: Loss of $\mathrm{B}$ cell regulatory function is associated with delayed healing in patients with tibia fracture. APMIS 2015, 123:975-985 
61. Sun G, Wang Y, Ti Y, Wang J, Zhao J, Qian H: Regulatory B cell is critical in bone union process through suppressing proinflammatory cytokines and stimulating Foxp3 in Treg cells. Clin Exp Pharmacol Physiol 2017, 44:455-462

62. Manabe N, Kawaguchi H, Chikuda H, Miyaura C, Inada M, Nagai R, Nabeshima Y, Nakamura K, Sinclair AM, Scheuermann RH, Kuro-o M: Connection between B lymphocyte and osteoclast differentiation pathways. J Immunol 2001, 167:2625-2631

63. Marusic A, Grcevic D, Katavic V, Kovacic N, Lukic IK, Kalajzic I, Lorenzo JA: Role of B lymphocytes in new bone formation. Lab Invest 2000, 80:1761-1774

64. Schell H, Lienau J, Epari DR, Seebeck P, Exner C, Muchow S, Bragulla H, Haas NP, Duda GN: Osteoclastic activity begins early and increases over the course of bone healing. Bone 2006, 38:547-554

65. Axmann R, Bohm C, Kronke G, Zwerina J, Smolen J, Schett G: Inhibition of interleukin-6 receptor directly blocks osteoclast formation in vitro and in vivo. Arthritis Rheum 2009, 60:2747-2756

66. Weitzmann MN, Cenci S, Rifas L, Haug J, Dipersio J, Pacifici R: T cell activation induces human osteoclast formation via receptor activator of nuclear factor kappaB ligand-dependent and -independent mechanisms. J Bone Miner Res 2001, 16:328-337

67. Gao Y, Morita I, Maruo N, Kubota T, Murota S, Aso T: Expression of IL-6 receptor and GP130 in mouse bone marrow cells during osteoclast differentiation. Bone 1998, 22:487-493

68. Duplomb L, Baud'huin M, Charrier C, Berreur M, Trichet V, Blanchard F, Heymann D: Interleukin-6 inhibits receptor activator of nuclear factor kappaB ligand-induced osteoclastogenesis by diverting cells into the macrophage lineage: key role of Serine727 phosphorylation of signal transducer and activator of transcription 3. Endocrinology 2008, 149:3688-3697

69. Kudo O, Sabokbar A, Pocock A, Itonaga I, Fujikawa Y, Athanasou NA: Interleukin- 6 and interleukin-11 support human osteoclast formation by a RANKL-independent mechanism. Bone 2003, 32:1-7

70. Franchimont N, Wertz S, Malaise M: Interleukin-6: an osteotropic factor influencing bone formation? Bone 2005, 37:601-606

71. Sims NA: Cell-specific paracrine actions of IL-6 family cytokines from bone, marrow and muscle that control bone formation and resorption. Int J Biochem Cell Biol 2016, 79:14-23 